\title{
Supplementary material for: Biogeochemistry and Physics of the Southern Ocean-Atmosphere System Explored With Data Science
}

Sebastian Landwehr ${ }^{1,13}$, Michele Volpi ${ }^{2}$, F. Alexander Haumann ${ }^{3,4}$, Charlotte M. Robinson ${ }^{5}$, Iris Thurnherr ${ }^{6,7}$, Valerio Ferracci ${ }^{8}$, Andrea Baccarini ${ }^{1,13}$, Jenny Thomas ${ }^{9}$, Irina Gorodetskaya ${ }^{10,11}$, Christian Tatzelt ${ }^{12}$, Silvia Henning ${ }^{12}$, Rob L. Modini ${ }^{13}$, Heather J. Forrer ${ }^{14,15}$, Yajuan Lin ${ }^{16,17,18}$, Nicolas Cassar ${ }^{16,17}$, Rafel Simó ${ }^{19}$, Christel Hassler ${ }^{20,9}$, Alireza Moallemi ${ }^{13}$, Sarah E. Fawcett ${ }^{14}$, Neil Harris ${ }^{8}$, Ruth Airs ${ }^{21}$, Marzieh H. Derkani ${ }^{22}$, Alberto Alberello ${ }^{23}$, Alessandro Toffoli ${ }^{22}$, Gang Chen ${ }^{13}$, Pablo Rodríguez-Ros ${ }^{19}$, Marina Zamanillo ${ }^{19}$, Pau Cortés-Greus ${ }^{19}$, Lei Xue ${ }^{24}$, Conor G. Bolas ${ }^{25}$, Katherine C. Leonard ${ }^{11,26}$, Fernando Perez-Cruz ${ }^{2}$, David Walton ${ }^{4,}$, and Julia Schmale ${ }^{1,13}$

${ }^{1}$ School of Architecture Civil and Environmental Engineering, École Polytechnique Fédérale de Lausanne, Switzerland

${ }^{2}$ Swiss Data Science Center, ETH Zurich and EPFL, Switzerland

${ }^{3}$ Atmospheric and Oceanic Sciences Program, Princeton University, Princeton, NJ, USA

${ }^{4}$ British Antarctic Survey, Cambridge, UK

${ }^{5}$ Remote Sensing and Satellite Research Group, School of Earth and Planetary Sciences, Curtin University, Kent Street, Bentley, WA 6102, Australia

${ }^{6}$ Institute for Atmospheric and Climate Science, ETH Zurich, Switzerland

${ }^{7}$ Geophysical Institute, University of Bergen, and Bjerknes Centre for Climate Research, Bergen, Norway

${ }^{8}$ Centre for Environmental and Agricultural Informatics, School of Water, Energy \& Environment Cranfield University, College Road, Cranfield MK43 0AL, Bedfordshire

${ }^{9}$ Swiss Polar Institute, Switzerland

${ }^{10}$ Centre for Environmental and Marine Studies, Department of Physics, University of Aveiro, Aveiro, Portugal

${ }^{11}$ CRYOS, School of Architecture, Civil and Environmental Engineering, École Polytechnique Fédérale de Lausanne, Switzerland

${ }^{12}$ Leibniz Institute for Tropospheric Research, Leipzig, Germany

${ }^{13}$ Laboratory of Atmospheric Chemistry, Paul Scherrer Institute (PSI), 5232 Villigen PSI, Switzerland

${ }^{14}$ Department of Oceanography, University of Cape Town, 7701, Cape Town, South Africa

${ }^{15}$ Earth, Ocean and Atmospheric Science Department, Florida State University, Tallahassee, FL, USA, 32306

${ }^{16}$ Division of Earth and Climate Sciences, Nicholas School of the Environment, Duke University, Durham, USA

${ }^{17}$ CNRS, Univ Brest, IRD, Ifremer, LEMAR, F-29280 Plouzané, France

${ }^{18}$ Duke Kunshan University, China

${ }^{19}$ Institut de Ciències del Mar (ICM-CSIC), Barcelona, Catalonia, Spain

${ }^{20}$ Department F.-A. Forel for Environmental and Aquatic Sciences, University of Geneva.

${ }^{21}$ Plymouth Marine Laboratory

${ }^{22}$ Dept. Infrastructure Engineering, Faculty of Engineering and Information Technology, The University of Melbourne, Melbourne, Australia

${ }^{23}$ Graduate School of Frontier Sciences, The University of Tokyo, Kashiwa, Japan

${ }^{24}$ Department of Chemistry, College of Environmental Science and Forestry, State University of New York, Syracuse, NY, USA

${ }^{25}$ ITOPF

${ }^{26}$ CIRES, University of Colorado Boulder, USA

${ }^{\dagger}$ deceased, 12 February 2019

Correspondence: Sebastian Landwehr (sebastian.landwehr@gmail.com) and Julia Schmale (julia.schmale@epfl.ch) 


\section{S1 Measurement methods and extraction of reanalysis data}

\section{S1.1 Operational meteorological observations}

Wind speed $\left(u_{31.5}, \mathrm{~ms}^{-1}\right)$ was measured with two 2-D sonic anemometers (model: WS425 and WMT702), situated on the main mast at 31.5 metres above sea level (m a.s.1.). The measurements were corrected for air-flow distortion and converted

5 to $u_{10 \mathrm{~N}}$, see (Landwehr et al., 2020). Downwelling solar radiation $\left(S_{\mathrm{in}}, \mathrm{W} \mathrm{m}^{-2}\right)$ was measured with two radiation sensors mounted on the main mast of the ship. Air temperature $\left(T_{\text {air }},{ }^{\circ} \mathrm{C}\right)$ and relative humidity $(\mathrm{RH}, \%)$ were measured at 23.7 $\mathrm{m}$ a.s.l. The barometric pressure $\left(P_{\text {air }}, \mathrm{hPa}\right)$ was measured at 20 metres above sea level. Sky cover (SC) and cloud level (CL) were measured with a Vaisala Ceilometer (model CL31). The meteorological data was recorded on-board as part of a Vaisala MAWS240 meteorological station and filtered for influences by the ship, e.g., the heat island effect on the leeward measurements of RH and $T_{\text {air }}$ and the shadowing of the radiation sensors by the ship's main mast, see (Landwehr et al., 2019).

\section{S1.2 Atmospheric dynamics based on numerical model data}

The surface cyclone mask records the presence of a surface cyclone at the ship's position. The passage of surface cyclones along the ACE ship track was calculated applying a 2D cyclone identification algorithm which identifies the outermost closed sea level pressure contour of a pressure minimum (Wernli and Schwierz, 2006; Sprenger et al., 2017) using the six-hourly global operational analysis data of the European Centre for Medium Range Weather Forecasts (ECMWF) and short-term forecasts in between the analysis time steps. The Lagrangian analysis tool LAGRANTO (Wernli and Davies, 1997; Sprenger and Wernli, 2015) was used to calculate five day air parcel backward trajectories using the ECMWF analysis data. The difference between sea surface and air temperature is used as a measure of cold and warm temperature advection. Warm temperature advection $\left(\right.$ mask $\left._{\mathrm{CW}}=+1\right)$ is defined to occur if the temperature difference is larger than $0^{\circ} \mathrm{C}$ and cold temperature advection $\left(\right.$ mask $\left._{\mathrm{CW}}=-1\right)$ if the difference is smaller than $0{ }^{\circ} \mathrm{C}$. The cold and warm temperature advection mask is calculated using the measured air temperature and sea surface temperature during ACE .

\section{S1.3 Precipitation}

Precipitation rates (rain and snow) are derived from Metek's micro-rain radar (MRR-2) measurements. The MRR-2 is a vertically pointing $24 \mathrm{GHz}$ frequency-modulated-continuous-wave (FMCW) Doppler radar. For rainfall, the drop size distribution and rainfall rate are derived using default Metek software following the method by Peters et al. (2005). In this study, the rainfall rate at 100 to 200 metres above sea level (m a.s.l.). at 1-minute resolution is used calculated from 10-min running mean (Gehring et al., 2020).

Snowfall rate ( $\mathrm{mm}$ w.e. $\mathrm{h}^{-1}$ ) estimated from MRR using a different approach than for rain. First, 1-minute vertical profiles of effective reflectivity (Z), Doppler velocity and spectral width are derived from raw MRR measurements using Maahn and Kollias (2012) algorithm (Gehring et al., 2020). Snowfall rate (SR) was then estimated using Z at $400 \mathrm{~m}$ a.g.l. range by applying different Z-S relationships (these relationships depend on snowfall microphysical properties) (see methodology details 
in Gorodetskaya et al., 2015). This includes Z-S relationships derived for two locations in Antarctica - at Dumont d'Urville (Grazioli et al., 2017) and at Princess Elisabeth station (Souverijns et al., 2017), as well as theoretical relationships for dry snow from Matrosov (2007) and Kulie and Bennartz (2009). As for sPCA analysis uncertainty cannot be taken into account, we applied the Z-S relationship derived for Dumont D’Urville as it has the closest geographical position to leg 2. This Z-S relationship is comparable to the theoretical relationship for aggregates derived by (Kulie and Bennartz, 2009). Microphysical snow observations during ACE showed a variety of microphysical properties (changing even during the same snowfall), implying that the chosen relationship does not represent all snowfall microphysical properties observed during ACE. For the sPCA analysis, variability in snowfall rate based on one Z-S relationship is assumed to be outweighing the impact of snow microphysical properties.

\section{S1.4 Horizontal hydrometeor flux}

Horizontal hydrometeor flux (HHF, $\mathrm{m}^{-2} \mathrm{~s}^{-1}$ ) was derived from Snow Particle Counter (SPC-95, manufactured by Niigata) measurements and wind speed measurements from the starboard anemometer (model: WS425). SPC detects particles from 36 micron providing particle size distribution between 36 and 490 micron and total particle count for particles $>500$ micron and until about $2 \mathrm{~mm}$. Here the total particle flux with sizes between 0.036 and $2 \mathrm{~mm}$ was provided. The HHF calculation includes correction for horizontal wind speed relative to the ship movement. HHF includes 1) snowfall and blowing snow during snowfall, 2) drifting/blowing snow lifted from the ground (snow on sea ice, snow from the ice sheet when the ship was in vicinity), 3) rain drops, 4) possibly sea spray.

\section{S1.5 Stable water isotope meteorology}

50 The mixing ratio and isotopic composition of atmospheric water vapour were measured continuously during ACE using a Picarro cavity ring-down spectrometer (model: L2130-i). The measurements were corrected for the humidity-isotope dependency and for the instrument's drift using a two-point slope correction and normalisation to Vienna Standard Mean Ocean Water 2 - Standard Light Antarctic Precipitation 2 (VSMOW2-SLAP2) according to the International Atomic Energy Agency (IAEA) recommendations (for details see Thurnherr et al., 2020a).

\section{S1.6 Atmospheric trace gases}

Isoprene mixing ratios in ambient air were monitored using the iDirac (Bolas et al., 2020), a custom built gas chromatograph with photoionisation detection (GC-PID). Routinely calibrated with gas standards traceable to a primary standard from the National Physical Laboratory (UK), the iDirac has a limit of detection of $40 \mathrm{ppt}$, precision of $10 \%$ and time resolution of $10 \mathrm{~min}$. The Isopreneair dataset was reanalysed following the sPCA. The revised values are within $\approx 30 \%$ of the version used for the sPCA and are available on Zenodo (10.5281/zenodo.3993391).

Ozone mixing ratio in air was measured with a 2BTechnologies ozone monitor (model 205). The instrument was compared against a calibrated ozone monitor after the campaign and measurements were corrected accordingly. 
Carbon dioxide, carbon monoxide and methane mixing ratios in air were measured with a PICARRO G2401 Gas Analyzer. The instrument was calibrated after the campaign using reference gases and measurements were corrected accordingly.

Sulfuric acid, iodic acid and MSA were measured with a nitrate chemical ionization mass spectrometer (an APi-HTOF mass spectrometer produced by Tofwerk AG coupled with a Chemical ionization inlet A70 produced by Airmodus were used). All species are detected in the mass spectrometer either as a deprotonated ion or as a cluster with the reagent ion $\left(\mathrm{NO}_{3}^{-}\right)$. The concentration is calculated as the area of these two peaks normalized to the concentration of the reagent ions (monomer, dimer and trimer) and multiplied by a calibration factor that was experimentally derived at Paul Scherrer Institute in the summer 2017, after the campaign. The concentration is also corrected for diffusional losses in the inlet line, the diffusion coefficient of sulfuric acid was used for all the three species.

\section{S1.7 Aerosols}

Instrumentation for in situ sampling of aerosol particles was situated in a measurement container during ACE and sampled ambient air by a shared standard aerosol inlet (Global Atmosphere Watch; Weingartner et al., 1999). An overview of instrumentation during ACE concerning aerosol particles is given in Schmale et al. (2019), with further instrument description in Walton and Thomas (2018).

The aerosol particle number size distribution (PNSD) in the submicron range (mobility diameter 11 to $400 \mathrm{~nm}$ ) was derived from measurements of two custom-built scanning mobility particle spectrometers (SMPSs) operated during ACE. Details on these SMPS instruments are given in Schmale et al. (2017). PNSDs in the coarse mode particle size range (aerodynamic diameter 0.7 to $19 \mu \mathrm{m}$ ) were obtained from measurements of an aerodynamic particle sizer (APS; model 3321 by TSI). A mode-fitting technique analogous to Modini et al. (2015) was used to combine PNSDs of SMPSs and APS instruments. The fitting procedure follows that described in Khlystov et al. (2004).

Cloud condensation nuclei (CCN) are aerosol particles capable of initiating droplet formation (Köhler, 1936) at certain levels of supersaturation (ss). CCN number concentrations at $s s=0.15 \%\left(N_{\mathrm{CCN}, 0.15}\right), 0.3 \%\left(N_{\mathrm{CCN}, 0.3}\right)$, and $1.0 \%\left(N_{\mathrm{CCN}, 1.0}\right)$ during ACE were obtained from measurements of a Cloud Condensation Nuclei counter (CCNc; type CCN-100 by Droplet Measurement Technique, Boulder, CA). Further documentation on the CCNc is given in Roberts and Nenes (2005).

The particle hygroscopicity parameter $\kappa$ for each $s s$ was derived using respective $N_{\mathrm{CCN}}(s s)$ and mode-fitted PNSD. Here, PNSDs were integrated along decreasing particle diameter, until the value of $N_{\mathrm{CCN}}$ is reached, which corresponds to a critical particle diameter $\left(D_{\text {crit }}(s s)\right) . \kappa$ as a function of $D_{\text {crit }}$ is given in Petters and Kreidenweis (2007).

Off-line filter sampling was performed during ACE with samplers situated on the upper bridge of the vessel and operated on PM10-inlets. High-volume ( $\mathrm{HiVol}, \sim 500 \mathrm{~L} \mathrm{~min}^{-1}$ ) sampling was performed with a DIGITEL filter sampler (type DHA80, Riemer Messtechnik, Germany) for 24 hours per quartz-fibre filter ( $14 \mathrm{~cm}$ diameter). In parallel to the HiVol sampling, an ultrasonic anemometer was run next to the filter sampler and provided data on wind direction, shutting down the sampling when wind came from the direction of the vessel's exhaust stack. Low-volume sampling (LoVol, $\sim 25 \mathrm{Lmin}^{-1}$ ) was performed using a DIGITEL filter sampler (DHA-14, Riemer Messtechnik, Germany) and sampling for eight hours (or two hours during periods 
of interest) on poly-carbonate membrane filters (type Nuclepore, Whatman, USA). Sampled filters were analysed regarding freezing behaviour ( $\mathrm{LoVol}$ and $\mathrm{HiVol}$ ) and ionic composition (HiVol only) of sampled material.

Ice-nucleating particles (INPs) are a subclass of aerosol particles, capable of initiating droplet freezing at temperatures above $-39^{\circ} \mathrm{C}$ (Pruppacher and Klett, 1997). The number concentration of INPs was derived for both HiVol and LoVol filters using a droplet freezing array at TROPOS, a set-up similar to that presented in Conen et al. (2012).

Mass concentrations for inorganic ions (ammonium, bromide, calcium, chloride, magnesium, nitrate, potassium, sodium, and sulfate), and organic constituents (methanesulfonic acid and oxalate) were measured by using ion chromatography on the HiVol filter contents. The ion chromatographic analysis was performed similar to Müller et al. (2010) and Van Pinxteren et al. (2017), using an ion chromatograph (type ICS3000 by Dionex, Sunnyvale, CA, USA).

The time-of-flight aerosol chemical speciation monitor (ToF-ACSM) is a time-of-flight mass spectrometry. It provides online continuous measurements of the chemical composition and mass of non-refractory submicron particles (NR-PM1), including nitrate, sulfate, ammonium, chloride, and organic compounds (Fröhlich et al., 2013). It is based on Aerodyne aerosol mass spectrometer (AMS) technology without a particle sizing feature, but it is stable, reliable, user-friendly, which makes it suitable for long-term monitoring purposes.

\section{S1.8 Physical and dynamical oceanography}

During ACE, surface and subsurface seawater properties were measured using a variety of sensors either connected to the continuous underway seawater supply (Haumann et al., 2020b) or mounted on the Conductivity-Temperature-Depth (CTD) rosette deployed during the cruise (Henry et al., 2020). Variables derived from these sensors that are used in this study include surface ocean temperature $\left(\mathrm{T}_{\mathrm{sw}},{ }^{\circ} \mathrm{C}\right)$, salinity $\left(\mathrm{S}_{\mathrm{sw}}, \mathrm{PSU}\right)$, and potential density anomaly $\left(\sigma_{0, s w}, \mathrm{~kg} \mathrm{~m}^{-3}\right)$. These variables are largely derived from the thermosalinograph connected to the underway line (Haumann et al., 2020b), which has been corrected using the surface ocean CTD data (Henry et al., 2020), surface ocean temperature data from Expendable Bathythermograph (XBT) probes (Haumann et al., 2020c), and discrete salinity samples collected from the underway line (Haumann et al., 2020a). The thermosalinograph data has undergone substantial post-processing and quality control described in detail by Haumann et al. (2020b). Temperature from the thermosalinograph has been merged with satellite-derived sea-surface temperature (Reynolds et al., 2007) that has been interpolated to the cruise track (Thomas and Pina Estany, 2019) and is being used whenever no thermosalinograph data was available. Salinity from the thermosalinograph has been merged with in-situ samples collected from the underway line and analysed in a salinometer (Haumann et al., 2020a) whenever no thermosalinograph data was available.

The surface ocean seawater oxygen isotopic composition $\left(\delta^{18} \mathrm{O}_{\mathrm{sw}}\right)$ was measured in discrete samples collected from the underway line using mass spectrometry (Haumann et al., 2019). Surface ocean mixed-layer depth (MLD) is estimated from both the CTD (Henry et al., 2020) and XBT (Haumann et al., 2020c) vertical temperature profiles using the temperature threshold criterion (de Boyer Montégut et al., 2004) and distributed by (Henry et al., 2020) and (Haumann et al., 2020c). In addition to the sensor and sample data collected during ACE, we interpolated satellite data (Haumann et al., 2020b) of seasurface height (SSH; http://marine.copernicus.eu), surface ocean geostrophic velocity ( $\mathrm{U}_{g}$; http://marine.copernicus.eu), and 
sea-ice concentration $\left(\mathrm{C}_{i}\right.$; Meier et al., 2013; Peng et al., 2013) to the cruise track (Thomas and Pina Estany, 2019) to fill gaps and better understand the physical and dynamical environmental conditions during the cruise.

Sea-state conditions were reconstructed using the ship motion (Nelli et al., 2020), which was recorded continuously by an inertial measurement unit (IMU) at a sampling rate of $1 \mathrm{~Hz}$ Alberello et al. (2020). In the frequency domain, the ship motion $S_{\text {ship }}(f)$ is linked to the incident wave field $S_{\text {wave }}(f)$ via the response amplitude operator $R(f)$ Newman (2018), i.e. $S_{\text {wave }}(f)=S_{\text {ship }}(f) / R(f)^{2}$. The motion spectra were retrieved by applying a Fourier Transformation to 5 min time series of the recorded vessel's motion and the response amplitude operator for the RV Akademik Tryoshnikov was calculated solving the equation of motion with the boundary element method solver, Nemoh Babarit and Delhommeau (2015). Based on the reconstructed sea state, integral wave parameters, significant wave height $\left(H_{s}=4 \sqrt{m_{0}}\right)$ and spectral mean wave period also known as wave energy period $\left(T_{m-10}=m_{-1} / m_{0}\right.$ with $\left.m_{n}=\int_{0}^{\infty} f^{n} S(f) d f\right)$, are obtained. The calculated significant wave height is compared against available satellite altimeter data Ribal and Young (2019). Due to the coarse resolution of satellite data, average values are computed for clusters with spatial resolution of $0.5^{\circ} \times 0.5^{\circ}$ and temporal resolution of $3 \mathrm{~h}$. There is a good agreement overall with root-mean squared error $(R M S E) \approx 0.4 \mathrm{~m}$, correlation coefficient $(R) \approx 0.94$, and scatter index $(S I) \approx 0.17$. Further details on sea state conditions during ACE are reported in Derkani et al. (2020).

In addition to the above variables that enter the analysis, we derived oceanic regions and frontal positions during the cruise to aid the interpretation of the results. These positions are shown as crosses e.g. in Figures 6 and 7 on the cruise track and comprise from north to south the Subtropical Front (STF), the Subantarctic Front (SAF), the Polar Front (PF), and the Southern Antarctic Circumpolar Current Front (SACCF). They are largely derived from the above described thermosalinograph and satellite data by investigating strong lateral gradients in $\mathrm{T}_{\mathrm{sw}}, \mathrm{S}_{\mathrm{sw}}$, or SSH (Haumann et al., 2020b) in close proximity of their climatological mean positions (black contours in Figures 6 and 7; Orsi et al., 1995). It should be noted that the choice of the frontal positions is somewhat subjective and might differ from their climatological mean position due to the availability of data and temporal variability.

\section{S1.9 Microbial, biogeochemical and optical properties}

Seawater was sampled from the underway seawater supply (Walton and Thomas, 2018) and preserved or analysed on-board for information on ocean microbial characteristics (chlorophyll $a$ concentration, phytoplankton chemotaxonomic pigment abundance, photosynthetic efficiency), ocean particle characteristics (particulate organic carbon and nitrogen, pigment degradation products, slope of the particle size distribution), dissolved nutrients (nitrate, nitrite, ammonium, phosphate and silicate concentrations) and optical properties (particulate absorption properties, coloured dissolved organic matter absorption). Additionally, irradiance over photosynthetically active wavelengths 400 to $700 \mathrm{~nm}$ was measured above the water and estimated in-water within the upper mixed layer. A complete description of all variables and associated dataset and methodology DOIs is available in Tables A7 and A8. Any additional methods not cited in Tables A7 and A8 are described here. The ACE Cruise Report (Walton and Thomas, 2018) provides further information on Project 1 objectives and sampling.

The relative abundance of phytoplankton taxonomic groups were derived from pigment concentrations (Antoine et al., 2019a) using the CHEMTAX v1.95 chemical taxonomy software (Mackey et al., 1996). Ten taxonomic groups were quantified: 
Chlorophytes type 1 (Chloro), cryptophytes type 2 (Crypto), diatoms type 1 (DiatA), diatoms type 2 (DiatB), dinoflagellates type 1 (Dino), haptophytes type 8 (Hapto8), haptophytes types $6+7$ (Hapto67), prasinophytes (Prasino), and pelagophytes (Pelago; Higgins et al., 2011). Prior to CHEMTAX analysis samples were standardised (mean subtracted and divided by standard deviation) and a dissimilarity matrix based on Manhattan's distances computed before being clustered using hierarchical clustering (Ward's method) in R version 3.5.0. Elbow, silhouette and gap tests confirmed 5 clusters as the best number of clusters for the dataset. CHEMTAX was then run on each cluster separately 60 times to derive optimised pigment ratio matrices for each cluster before a final 20 runs determined taxonomic abundances $\left(\mathrm{mg} \mathrm{m}^{-3}\right)$ for each cluster. The initial pigment ratios were compiled from Rodriguez et al. (2002), Zapata et al. (2000), Cook et al. (2011), Higgins et al. (2011), Cassar et al. (2015), and Nunes et al. (2019). To increase the resolution of discrete estimates of phytoplankton total chlorophyll $a$ concentration $\left(\mathrm{mg} \mathrm{m}^{-3}\right)$, the dataset of total chlorophyll $a$ concentration derived via high performance liquid chromatography (Antoine et al., 2019b), total chlorophyll $a$ was also determined using the absorption line height method of Roesler and Barnard (2013) where particulate absorption data was available (Antoine et al., 2021). The slope of the particle size distribution ( $\mathrm{PSD}_{s}$ lope; 2 to $60 \mu \mathrm{m}$ ) was calculated from a linear regression of $\log _{10}$ transformed particle concentration vs bin diameter. Measurements of particle size distribution were made on a Beckmann Multisizer 3 Coulter counter with a $100 \mu \mathrm{m}$ aperture tube detecting particles in the range of 2 to $60 \mu \mathrm{m}$ across 400 bins. Counts were converted to particles per $\mathrm{m}^{3}$ and samples with high noise or particles constrained to just a few bins were removed. The ratio of non-algal absorption to total particulate absorption at $440 \mathrm{~nm}\left(a_{\mathrm{nap}} / a_{\mathrm{p}}\right)$ was calculated using the particulate absorption at (Antoine et al., 2021). Absorption by non-algal properties was determined algebraically using an iterative best-fit approach of Bricaud and Stramski (1990) to determine the absorption slope of non-algal particles. The slope of non-algal absorption from 380 to $700 \mathrm{~nm}$ ( $\left.a_{\text {napslope }}\right)$ was modelled as an exponential decay from reference wavelength $380 \mathrm{~nm}$ as per Clementson et al. (2004). Absorption due to coloured dissolved organic matter at $350 \mathrm{~nm}\left(a_{\mathrm{CDOM}}\right)$ was derived by subtracting particulate absorption at $350 \mathrm{~nm}$ (Antoine et al., 2021) from the total organic matter absorption at $350 \mathrm{~nm}$. Photosynthetic efficiency of photosystem II $\left(\mathrm{F}_{\mathrm{V}} \mathrm{F}_{\mathrm{M}}\right.$ and $\left.\Phi_{\mathrm{PSII}}^{\prime}\right)$ and the absorption cross section of photosystem II $\left(\sigma_{P S I I}, \AA^{2} \mathrm{RCII}^{-1}\right)$ and $\left(\sigma_{P S I I}^{*}, \AA^{2} \mathrm{RCII}^{-1}\right)$ were measured using Fast Repetition Rate fluorometry (FRRf) and parameters derived using the python phyto_photo_utils toolbox as per Ryan-Keogh and Robinson (2021). Datapoints were classified as nighttime (dark; $\mathrm{F}_{\mathrm{V}} \mathrm{F}_{\mathrm{M}}$ and $\sigma_{P S I I}$ ) and daytime ( $\Phi_{\mathrm{PSII}}^{\prime}$ and $\sigma_{P S I I}^{\prime}$ ) measurements using the sun angle as a proxy for nightime and daytime where sun angle $>5^{\circ}$ is considered nighttime (or dark measurement conditions). The median light intensity $\left(I_{\mathrm{g}}, \mu \mathrm{mol}\right.$ photons $\left.m^{-2} s^{-1}\right)$ over photosynthetically active wavelengths (PAR, $\mu$ mol photons $m^{-2} s^{-1}$ ) within the mixed layer was estimated at 3 hourly time intervals along the ACE ship track. First, to derive an estimate of the light attenuation coefficient $\left(\mathrm{K}_{\mathrm{d}} \mathrm{PAR}, \mathrm{m}^{-1}\right)$, estimates of total chlorophyll $a$ and pheopigments were linearly interpolated to 3 hourly intervals and then $\mathrm{K}_{\mathrm{d}}$ PAR calculated as per Morel (1988) using the sum of total chlorophyll $a$ and pheopigments. The mixed layer depth (m) was linearly interpolated at 3 hourly intervals from the combined CTD and XBT datasets of Haumann et al. (2020c). At each 3 hour time point, the average sky irradiance over PAR wavelengths (avPAR(0), $\mu$ mol photons $m^{-2} s^{-1}$ ) over the preceding 24 hours (and in some cases up to 72 hours where data was lacking) was calculated using the 1 minute resolution $\operatorname{PAR}(0)$ dataset (Thomalla et al., 2020). At each 3 hour time point, the average PAR over 24 hours at 1 metre intervals (z) 
down to the mixed layer depth was calculated as $\operatorname{avPAR}(\mathrm{z})=\operatorname{avPAR}(0) \mathrm{e}^{-\mathrm{KdPAR} \cdot \mathrm{z}}$ (equation 6.2; Kirk, 1994). Finally $I_{\mathrm{g}}$ was calculated at each 3 hour time point as the median $\operatorname{avPAR}(\mathrm{z})$ from the surface to the mixed layer depth.

200

\section{dissolved volatiles}

Bacteria, cyanobacteria, and phototrophic picoeukaryotes and nanoeukaryotes were counted by flow cytometry. Seawater samples were aliquoted in cryovials, fixed (killed) by addition of $1 \%$ paraformaldehyde plus $0.05 \%$ glutaraldehyde (final concentrations), and stored at $-80^{\circ} \mathrm{C}$. In the lab on land, samples were thawed and analysed with a PARTEC Cube 8 flow cytometer equipped with a laser emitting at $488 \mathrm{~nm}$. Heterotrophic bacteria were counted by their signature in a plot of side scatter versus green fluorescence after being stained with $10 \mu \mathrm{M}$ of SYBRGreen I. In separate runs of unstained samples, cyanobacteria (Prochlorococcus and Synechococcus), picoeukaryotes and nanoeukaryotes were identified and enumerated on the basis of the differences in autofluorescence and light scattering characteristics. In both cases, yellow-green $0.92 \mu \mathrm{m}$ latex beads were added as an internal standard. The in vivo fluorescence of phytoplankton chlorophyll $a$ was measured continuously with an WetLabs ECO sensor positioned in the shipboard surface seawater pumping line.

Concentrations of transparent exopolymeric particles (TEP) were determined by spectrophotometry following Passow and Alldredge (1995). Duplicate samples (150 to $300 \mathrm{~mL}$ ) were filtered through $25 \mathrm{~mm}$ diameter $0.4 \mu \mathrm{m}$ pore size Polycarbonate filters (DHI) and the filters were immediately stained with $500 \mu \mathrm{L}$ of Alcian blue solution $(0.02 \%, \mathrm{pH} 2.5)$ for $5 \mathrm{~s}$, rinsed with Milli-Q water and stored frozen. Duplicate blanks (empty stained filters) were prepared at every station. In the lab on land, all sample and blank filters were soaked in $5 \mathrm{~mL}$ of $80 \%$ sulfuric acid and shaken intermittently for $3 \mathrm{~h}$. The samples were then measured spectrophotometrically at $787 \mathrm{~nm}$ (Varian Cary spectrophotometer). An Alcian blue dye solution calibration was prepared using a standard solution of Xanthan Gum (XG).

Concentrations of Coomassie stainable particles (CSP) were determined by spectrophotometry following (Cisternas-Novoa et al., 2014). Duplicate samples (150 to $300 \mathrm{~mL}$ ) were filtered through $25 \mathrm{~mm}$ diameter $0.4 \mu \mathrm{m}$ pore size Polycarbonate filters (Whatman) using a constant low filtration pressure $(\approx 150 \mathrm{mmHg})$. The samples were immediately stained with $700 \mu \mathrm{L}$ of a working Coomassie Brilliant Blue (CBB-G 250) solution (0.04\%, pH 7.4) for $30 \mathrm{~s}$, rinsed with Milli-Q water and stored frozen. Duplicate blanks (empty filters stained as stated earlier) were prepared at every station. In the lab on land, both the sample and blank filters were soaked in $4 \mathrm{~mL}$ of extraction solution (3\% SDS in 50\% isopropyl alcohol; Ball, 1986) and sonicated in a water bath for $2 \mathrm{~h}$ at $37^{\circ} \mathrm{C}$. The samples were then measured spectrophotometrically at $615 \mathrm{~nm}$ (Shimadzu UVVis spectrophotometer UV120). The CBB dye solution calibrations were prepared with bovine albumina using three filtered seawater samples of different salinities collected during the cruise.

To determine concentrations of total (dissolved and particulate) dimethylsulfoniopropionate (DMSP) and acrylate, aliquots $(15 \mathrm{ml}$ ) of seawater samples were heated to initial boiling in a microwave, $150 \mu \mathrm{l}$ of $36 \% \mathrm{HCl}$ was added and they were stored at room temperature. Back to land, the samples were analysed for DMSP by alkaline hydrolysis to DMS overnight and analysis of the latter using a cryogenic purge-and-trap system and gas chromatography. Acrylate concentrations were determined using pre-column derivatization with TSA, separation by HPLC and UV detection. 
Aqueous concentrations of volatile organic compounds (VOCs) carbonyl sulfide (OCS), carbon disulfide $\left(\mathrm{CS}_{2}\right)$, dimethyl sulfide (DMS), isoprene $\left(\mathrm{C}_{5} \mathrm{H}_{8}\right)$ and bromomethanes $\left(\mathrm{CHBr}_{3}, \mathrm{CH}_{2} \mathrm{Br}_{2}\right)$ were measured on board with a purge and trap (Stratum, Tekmar Teledink) gas chromatography-mass spectrometry (5975-T LTM-GC/MSL, Agilent Technologies) system. Seawater samples were taken from the Niskin bottles or the underway tap with glass bottles with glass caps, leaving no head space. Subsamples of $25 \mathrm{ml}$ were withdrawn with a glass syringe and filtered through GF/F filters while introduced to the system, where they were sparged for $12 \mathrm{~min}$ with ultrapure $\mathrm{He}(40 \mathrm{~mL} / \mathrm{min})$. VOCs were trapped on a VOCARB 3000 absorption column, desorbed by heating to $250^{\circ} \mathrm{C}$, and separated in a LTM DB-VRX capillary column held 4 min at $35^{\circ} \mathrm{C}$ and subsequently heated to $230^{\circ} \mathrm{C}$ at $30^{\circ} \mathrm{Cmin}^{-1}$. The MS data acquisition was performed by selected ion monitoring of the most characteristic 240 fragments of each compound. Duplicates were run. Calibrations were run with standard solutions in methanol, except for OCS, which was calibrated against a gaseous mixture in nitrogen. 
Figures S1 to S4 provide the weight distributions of the LV master and bootstrap runs. For each LV the OV weights are displayed for the master run and the distributions of the bootstrap runs are displayed as boxplots. 


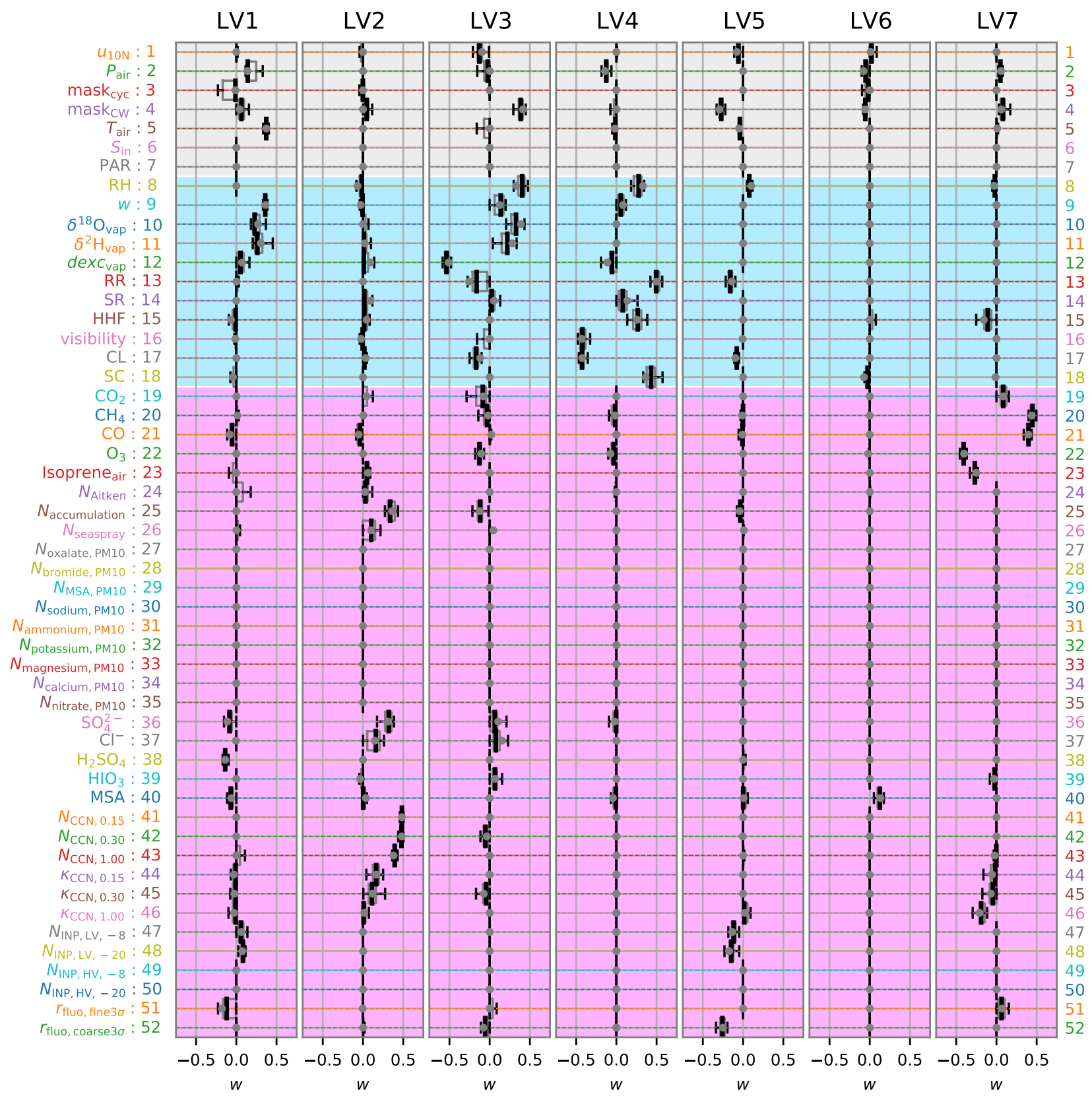

Figure S1. (part 1 of 4) Weight distributions of the LV master and bootstrap runs. OV indices are represented on the y-axis, while the x-axis represents the magnitude of the weights for each LV. The weights of the master run are denoted as gray bullet and the distribution of the weights of the bootstrap runs are shown as box and whisker plots for each OV. Thin and thick black lines indicate zero and non-zero median values, respectively, the boxes represent the interquartile range, and the whiskers represent the 1st and the 9th decile. The background colours signal the OV categories (see Table 1). 


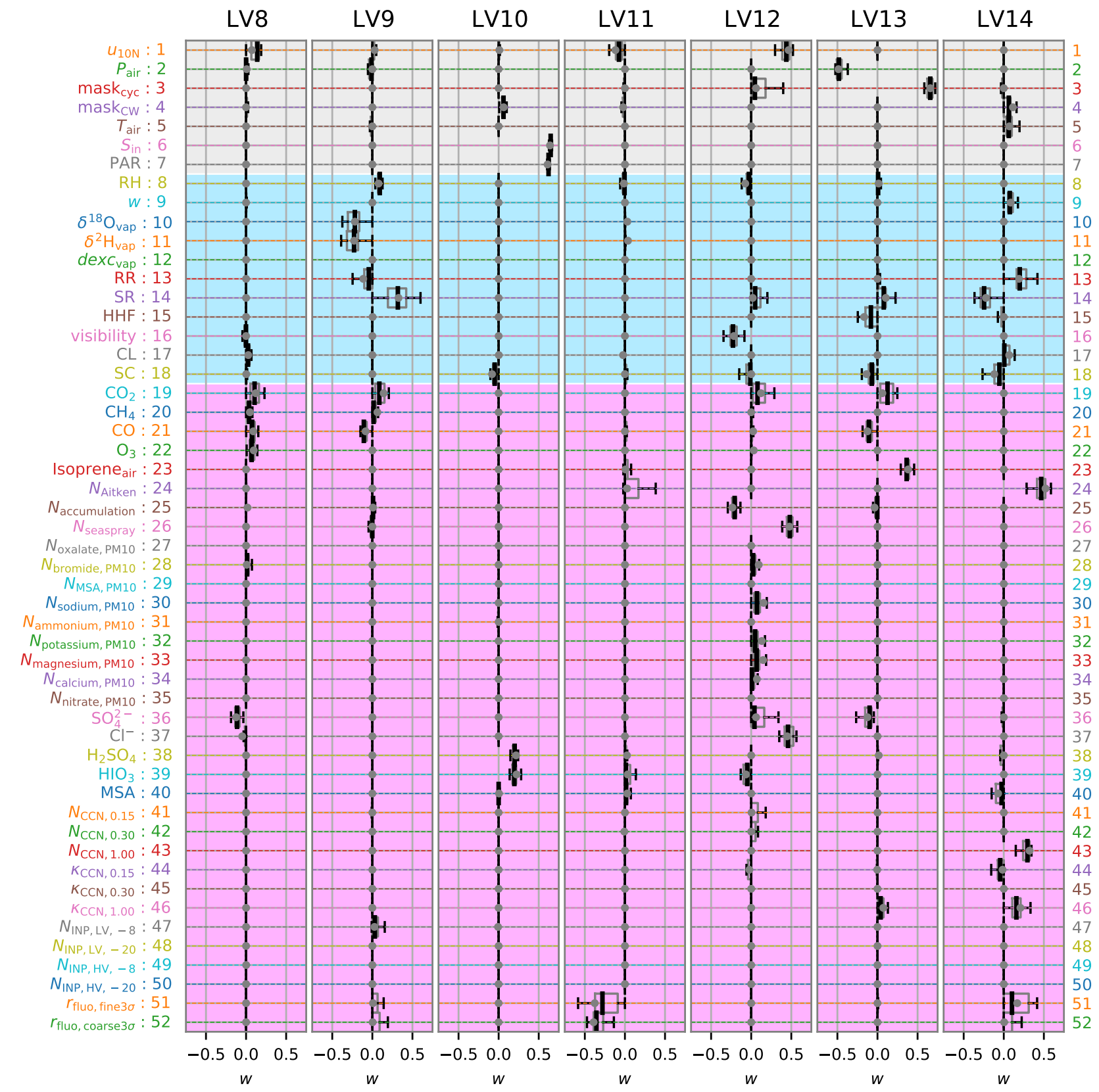

Figure S2. (part 2 of 4) 


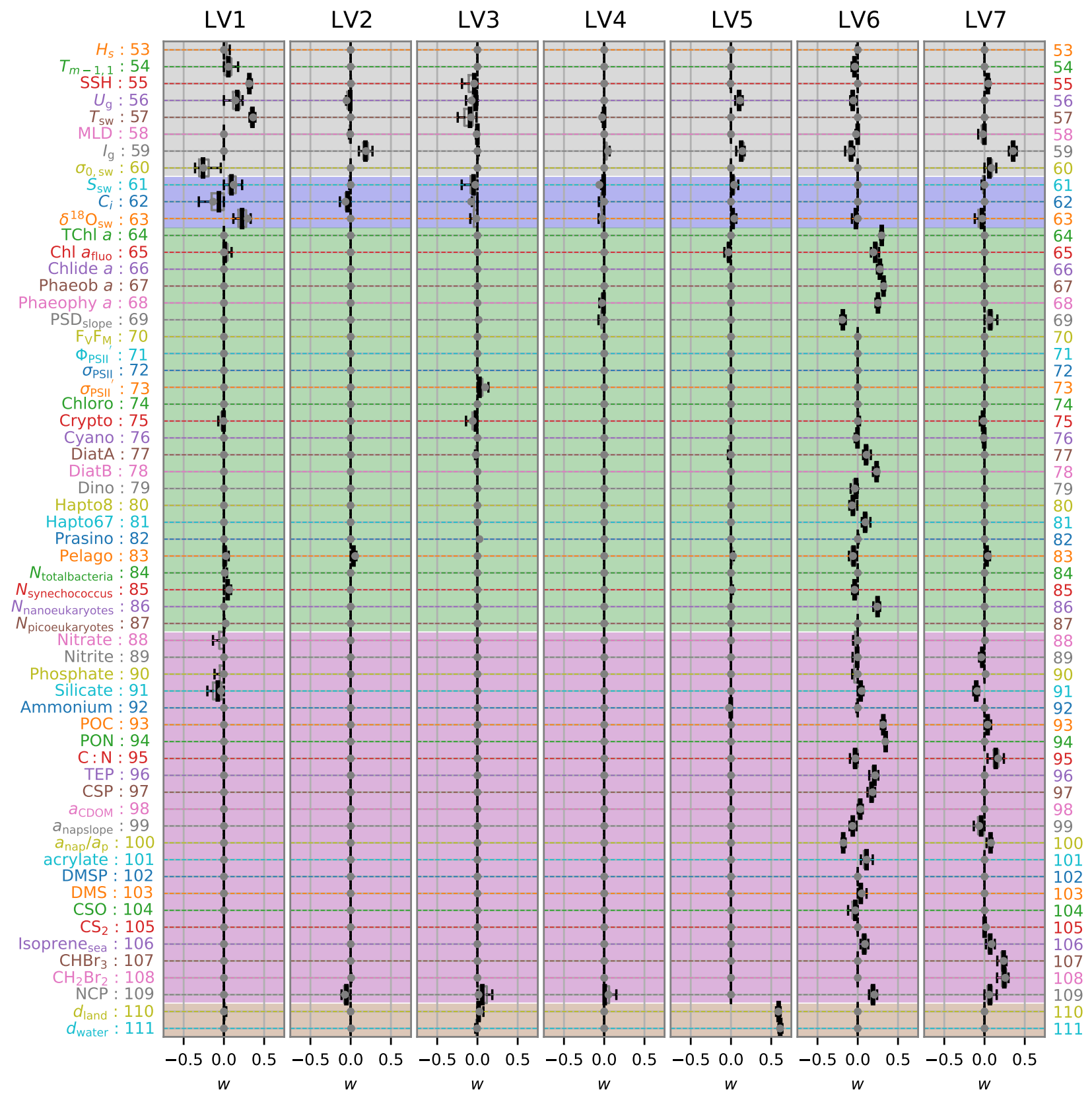

Figure S3. (part 3 of 4) 


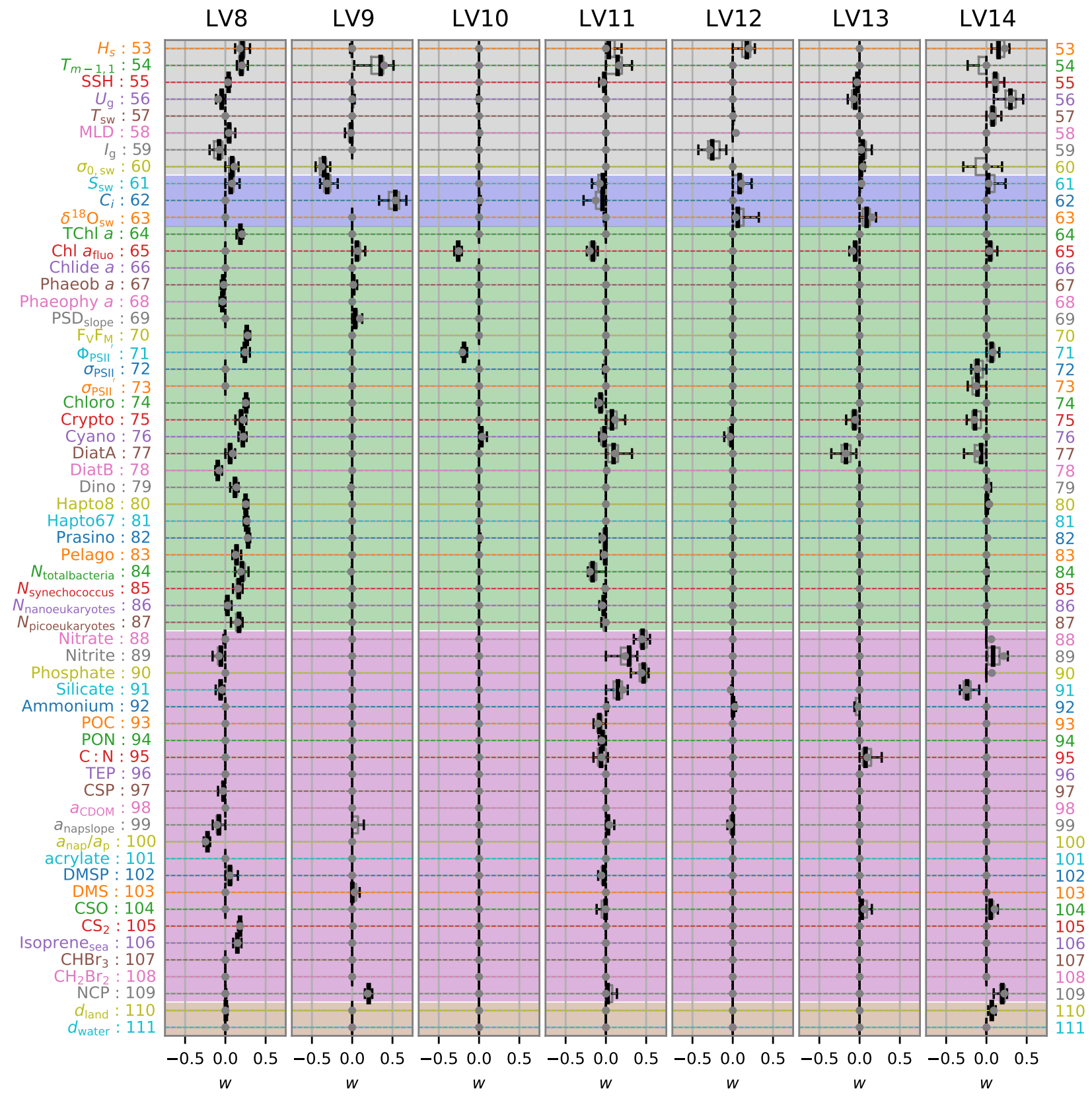

Figure S4. (part 4 of 4) 
Here we provide detailed information on the OV weight vectors for each LV. The tables S1 to S15 provide the median weight $w$, the estimate of the bootstrap standard deviation $\sigma$, which is calculated as 1.4826 times the median standard deviation over the 30 bootstrap runs and the ratio $\sigma \bar{w}^{-1}$. The OVs are provided in the order of their significance given by $\sigma \bar{w}^{-1}$ and their rank according to the median weight is given in the third column. 
Table S1. List of OVs contributing to LV1 - Climatic zones and large-scale horizontal gradients, whith $\sigma \bar{w}^{-1}>1$. The OVs are sorted according to $\sigma \bar{w}^{-1}>1$ (

\begin{tabular}{|c|c|c|c|c|c|}
\hline OV-ID & Symbol & Rank & $\bar{w}$ & $\sigma$ & $\sigma \bar{w}^{-1}$ \\
\hline OV5 & $T_{\text {air }}$ & 1 & 0.372 & 0.014 & 27.3 \\
\hline OV9 & $w$ & 2 & 0.360 & 0.011 & 32.0 \\
\hline OV57 & $T_{\mathrm{sw}}$ & 3 & 0.355 & 0.024 & 14.9 \\
\hline OV55 & SSH & 4 & 0.316 & 0.017 & 18.9 \\
\hline OV11 & $\delta^{2} \mathrm{H}_{\mathrm{vap}}$ & 5 & 0.262 & 0.053 & 4.9 \\
\hline OV60 & $\sigma_{0, \mathrm{sw}}$ & 6 & -0.260 & 0.080 & 3.2 \\
\hline OV10 & $\delta^{18} \mathrm{O}_{\text {vap }}$ & 7 & 0.229 & 0.060 & 3.8 \\
\hline OV63 & $\delta^{18} \mathrm{O}_{\mathrm{sw}}$ & 8 & 0.226 & 0.074 & 3.1 \\
\hline OV56 & $U_{\mathrm{g}}$ & 9 & 0.166 & 0.063 & 2.6 \\
\hline OV2 & $P_{\text {air }}$ & 10 & 0.143 & 0.023 & 6.3 \\
\hline OV38 & $\mathrm{H}_{2} \mathrm{SO}_{4}$ & 11 & -0.139 & 0.019 & 7.5 \\
\hline OV51 & $r_{\text {fluo,fine } 3 \sigma}$ & 12 & -0.119 & 0.093 & 1.3 \\
\hline OV61 & $S_{\mathrm{sw}}$ & 13 & 0.094 & 0.062 & 1.5 \\
\hline OV36 & $\mathrm{SO}_{4}^{2-}$ & 14 & -0.084 & 0.038 & 2.2 \\
\hline OV48 & $N_{\text {INP }, \mathrm{LV},-20}$ & 15 & 0.082 & 0.024 & 3.4 \\
\hline OV40 & MSA & 17 & -0.069 & 0.026 & 2.6 \\
\hline OV4 & mask $_{\mathrm{CW}}$ & 18 & 0.064 & 0.047 & 1.4 \\
\hline OV47 & $N_{\text {INP,LV },-8}$ & 20 & 0.057 & 0.045 & 1.3 \\
\hline OV21 & $\mathrm{CO}$ & 22 & -0.052 & 0.051 & 1.0 \\
\hline OV85 & $N_{\text {synechococcus }}$ & 24 & 0.046 & 0.018 & 2.5 \\
\hline
\end{tabular}


Table S2. List of OVs contributing to LV2 - Drivers of cloud condensation nuclei population, whith $\sigma \bar{w}^{-1}>1$. The OVs are sorted according to $\sigma \bar{w}^{-1}>1$ (sixed column). The order rank according to $|w|$ is provided in the third column.

\begin{tabular}{llllll}
\hline OV-ID & Symbol & Rank & $\bar{w}$ & $\sigma$ & $\sigma \bar{w}^{-1}$ \\
\hline OV41 & $N_{\mathrm{CCN}, 0.15}$ & 1 & 0.484 & 0.014 & 35.5 \\
OV42 & $N_{\mathrm{CCN}, 0.30}$ & 2 & 0.478 & 0.020 & 24.2 \\
OV43 & $N_{\mathrm{CCN}, 1.00}$ & 3 & 0.394 & 0.016 & 24.7 \\
OV25 & $N_{\text {accumulation }}$ & 4 & 0.339 & 0.053 & 6.4 \\
OV36 & $\mathrm{SO}_{4}^{2-}$ & 5 & 0.320 & 0.056 & 5.7 \\
OV59 & $I_{\mathrm{g}}$ & 6 & 0.184 & 0.046 & 4.0 \\
OV44 & $\kappa_{\mathrm{CCN}, 0.15}$ & 7 & 0.164 & 0.054 & 3.0 \\
OV37 & $\mathrm{Cl}^{-}$ & 8 & 0.160 & 0.084 & 1.9 \\
OV45 & $\kappa_{\mathrm{CCN}, 0.30}$ & 9 & 0.112 & 0.071 & 1.6 \\
OV26 & $N_{\text {seaspray }}$ & 10 & 0.102 & 0.084 & 1.2 \\
OV109 & NCP & 11 & -0.053 & 0.039 & 1.4 \\
OV23 & Isoprene & 12 & 0.049 & 0.031 & 1.6 \\
OV4 & mask & 13 & 0.046 & 0.034 & 1.4 \\
OV21 & CO & 14 & -0.038 & 0.025 & 1.5 \\
OV83 & Pelago & 16 & 0.035 & 0.033 & 1.1 \\
\hline
\end{tabular}


Table S3. List of OVs contributing to LV3 - Meridional cold and warm air advection, whith $\sigma \bar{w}^{-1}>1$. The OVs are sorted according to $\sigma \bar{w}^{-1}>1$ (sixed column). The order rank according to $|w|$ is provided in the third column.

\begin{tabular}{llllll}
\hline OV-ID & Symbol & Rank & $\bar{w}$ & $\sigma$ & $\sigma \bar{w}^{-1}$ \\
\hline OV12 & dexc & 1 & -0.537 & 0.031 & 17.5 \\
OV8 & $\mathrm{RH}$ & 2 & 0.404 & 0.066 & 6.2 \\
OV4 & mask $_{\mathrm{CW}}$ & 3 & 0.385 & 0.038 & 10.2 \\
OV10 & $\delta^{18} \mathrm{O}_{\text {vap }}$ & 4 & 0.328 & 0.037 & 8.8 \\
OV11 & $\delta^{2} \mathrm{H}_{\text {vap }}$ & 5 & 0.219 & 0.036 & 6.0 \\
OV17 & $\mathrm{CL}$ & 6 & -0.168 & 0.042 & 4.0 \\
OV13 & $\mathrm{RR}$ & 7 & -0.162 & 0.116 & 1.4 \\
OV9 & $w$ & 8 & 0.137 & 0.066 & 2.1 \\
OV1 & $u_{10 \mathrm{~N}}$ & 9 & -0.128 & 0.038 & 3.4 \\
OV22 & $\mathrm{O}_{3}$ & 10 & -0.127 & 0.025 & 5.1 \\
OV25 & $N_{\text {accumulation }}$ & 11 & -0.117 & 0.044 & 2.7 \\
OV57 & $T_{\mathrm{sw}}$ & 12 & -0.092 & 0.055 & 1.7 \\
OV19 & $\mathrm{CO}_{2}$ & 13 & -0.086 & 0.067 & 1.3 \\
OV37 & $\mathrm{Cl}^{-}$ & 14 & 0.077 & 0.047 & 1.6 \\
OV39 & $\mathrm{HIO}_{3}$ & 15 & 0.066 & 0.034 & 1.9 \\
OV52 & $r_{\text {fluo,coarse3 } \sigma}$ & 18 & -0.055 & 0.039 & 1.4 \\
OV42 & $N_{\mathrm{CCN}, 0.30}$ & 19 & -0.054 & 0.047 & 1.2 \\
\hline
\end{tabular}

Table S4. List of OVs contributing to LV4 - Precipitation vs. dry conditions, whith $\sigma \bar{w}^{-1}>1$. The OVs are sorted according to $\sigma \bar{w}^{-1}>1$ (sixed column). The order rank according to $|w|$ is provided in the third column.

\begin{tabular}{llllll}
\hline OV-ID & Symbol & Rank & $\bar{w}$ & $\sigma$ & $\sigma \bar{w}^{-1}$ \\
\hline OV13 & RR & 1 & 0.495 & 0.049 & 10.1 \\
OV18 & SC & 2 & 0.432 & 0.079 & 5.4 \\
OV17 & CL & 3 & -0.427 & 0.029 & 14.9 \\
OV16 & visibility & 4 & -0.423 & 0.048 & 8.9 \\
OV8 & RH & 5 & 0.276 & 0.072 & 3.8 \\
OV15 & HHF & 6 & 0.265 & 0.076 & 3.5 \\
OV2 & $P_{\text {air }}$ & 7 & -0.125 & 0.027 & 4.7 \\
OV14 & SR & 8 & 0.080 & 0.072 & 1.1 \\
OV9 & $w$ & 10 & 0.055 & 0.054 & 1.0 \\
\hline
\end{tabular}


Table S5. List of OVs contributing to LV5 - Distance to land, whith $\sigma \bar{w}^{-1}>1$. The OVs are sorted according to $\sigma \bar{w}^{-1}>1$ (sixed column). The order rank according to $|w|$ is provided in the third column.

\begin{tabular}{llllll}
\hline OV-ID & Symbol & Rank & $\bar{w}$ & $\sigma$ & $\sigma \bar{w}^{-1}$ \\
\hline OV111 & $d_{\text {water }}$ & 1 & 0.612 & 0.013 & 45.7 \\
OV110 & $d_{\text {land }}$ & 2 & 0.592 & 0.014 & 41.0 \\
OV4 & mask $_{\mathrm{CW}}$ & 3 & -0.271 & 0.028 & 9.7 \\
OV52 & $r_{\text {fluo,coarse3 } \sigma}$ & 4 & -0.257 & 0.043 & 5.9 \\
OV13 & RR & 5 & -0.158 & 0.033 & 4.9 \\
OV48 & $N_{\text {INP,LV },-20}$ & 6 & -0.147 & 0.034 & 4.3 \\
OV59 & $I_{\mathrm{g}}$ & 7 & 0.126 & 0.030 & 4.2 \\
OV47 & $N_{\text {INP,LV },-8}$ & 8 & -0.118 & 0.033 & 3.6 \\
OV56 & $U_{\mathrm{g}}$ & 9 & 0.102 & 0.023 & 4.4 \\
OV17 & CL & 10 & -0.079 & 0.017 & 4.7 \\
OV8 & RH & 11 & 0.077 & 0.012 & 6.5 \\
OV1 & $u_{10 \mathrm{~N}}$ & 12 & -0.057 & 0.024 & 2.4 \\
OV5 & $T_{\text {air }}$ & 13 & -0.040 & 0.008 & 5.3 \\
OV25 & $N_{\text {accumulation }}$ & 14 & -0.034 & 0.017 & 1.9 \\
\hline
\end{tabular}


Table S6. List of OVs contributing to LV6 - Iron-fertilized biological productivity, whith $\sigma \bar{w}^{-1}>1$. The OVs are sorted according to $\sigma \bar{w}^{-1}>1$ (sixed column). The order rank according to $|w|$ is provided in the third column.

\begin{tabular}{|c|c|c|c|c|c|}
\hline OV-ID & Symbol & Rank & $\bar{w}$ & $\sigma$ & $\sigma \bar{w}^{-1}$ \\
\hline OV94 & PON & 1 & 0.347 & 0.010 & 36.2 \\
\hline OV67 & Phaeob $a$ & 2 & 0.320 & 0.008 & 40.5 \\
\hline OV93 & POC & 3 & 0.318 & 0.011 & 27.8 \\
\hline OV64 & TChl $a$ & 4 & 0.298 & 0.008 & 35.1 \\
\hline OV66 & Chlide $a$ & 5 & 0.275 & 0.013 & 20.5 \\
\hline OV68 & Phaeophy $a$ & 6 & 0.251 & 0.013 & 18.7 \\
\hline OV86 & $N_{\text {nanoeukaryotes }}$ & 7 & 0.247 & 0.022 & 11.3 \\
\hline OV78 & DiatB & 8 & 0.235 & 0.019 & 12.2 \\
\hline OV65 & Chl $a_{\text {fluo }}$ & 9 & 0.217 & 0.032 & 6.9 \\
\hline OV96 & TEP & 10 & 0.207 & 0.024 & 8.6 \\
\hline OV109 & $\mathrm{NCP}$ & 11 & 0.190 & 0.030 & 6.2 \\
\hline OV69 & $\mathrm{PSD}_{\text {slope }}$ & 12 & -0.185 & 0.020 & 9.2 \\
\hline OV100 & $a_{\text {nap }} / a_{\mathrm{p}}$ & 13 & -0.181 & 0.014 & 12.7 \\
\hline OV97 & CSP & 14 & 0.171 & 0.025 & 6.7 \\
\hline OV40 & MSA & 15 & 0.126 & 0.028 & 4.4 \\
\hline OV101 & acrylate & 16 & 0.110 & 0.034 & 3.2 \\
\hline OV77 & DiatA & 17 & 0.103 & 0.020 & 5.1 \\
\hline OV81 & Hapto67 & 18 & 0.091 & 0.028 & 3.2 \\
\hline OV59 & $I_{\mathrm{g}}$ & 19 & -0.082 & 0.020 & 4.2 \\
\hline OV106 & Isoprene $_{\text {sea }}$ & 20 & 0.080 & 0.034 & 2.4 \\
\hline OV56 & $U_{\mathrm{g}}$ & 21 & -0.062 & 0.025 & 2.5 \\
\hline OV99 & $a_{\text {napslope }}$ & 22 & -0.062 & 0.017 & 3.7 \\
\hline OV80 & Hapto8 & 23 & -0.061 & 0.025 & 2.4 \\
\hline OV4 & mask $_{\mathrm{CW}}$ & 24 & -0.056 & 0.011 & 5.3 \\
\hline OV2 & $P_{\text {air }}$ & 25 & -0.052 & 0.032 & 1.6 \\
\hline OV83 & Pelago & 26 & -0.051 & 0.040 & 1.3 \\
\hline OV54 & $T_{m-1,1}$ & 27 & -0.041 & 0.033 & 1.2 \\
\hline OV85 & $N_{\text {synechococcus }}$ & 28 & -0.040 & 0.024 & 1.7 \\
\hline OV103 & DMS & 29 & 0.038 & 0.029 & 1.3 \\
\hline OV91 & Silicate & 30 & 0.036 & 0.032 & 1.1 \\
\hline OV98 & $a_{\mathrm{CDOM}}$ & 32 & 0.031 & 0.023 & 1.4 \\
\hline
\end{tabular}


Table S7. List of OVs contributing to LV7 - Seasonal signal, whith $\sigma \bar{w}^{-1}>1$. The OVs are sorted according to $\sigma \bar{w}^{-1}>1$ (sixed column). The order rank according to $|w|$ is provided in the third column.

\begin{tabular}{|c|c|c|c|c|c|}
\hline OV-ID & Symbol & Rank & $\bar{w}$ & $\sigma$ & $\sigma \bar{w}^{-1}$ \\
\hline OV20 & $\mathrm{CH}_{4}$ & 1 & 0.448 & 0.027 & 16.4 \\
\hline OV22 & $\mathrm{O}_{3}$ & 2 & -0.407 & 0.018 & 22.5 \\
\hline OV21 & $\mathrm{CO}$ & 3 & 0.398 & 0.023 & 17.5 \\
\hline OV59 & $I_{\mathrm{g}}$ & 4 & 0.356 & 0.022 & 16.1 \\
\hline OV23 & Isoprene $_{\text {air }}$ & 5 & -0.270 & 0.025 & 10.6 \\
\hline OV108 & $\mathrm{CH}_{2} \mathrm{Br}_{2}$ & 6 & 0.246 & 0.038 & 6.4 \\
\hline OV107 & $\mathrm{CHBr}_{3}$ & 7 & 0.238 & 0.031 & 7.7 \\
\hline OV46 & $\kappa_{\mathrm{CCN}, 1.00}$ & 8 & -0.191 & 0.043 & 4.4 \\
\hline OV95 & $\mathrm{C}: \mathrm{N}$ & 9 & 0.139 & 0.044 & 3.2 \\
\hline OV15 & HHF & 10 & -0.110 & 0.069 & 1.6 \\
\hline OV91 & Silicate & 11 & -0.103 & 0.021 & 5.0 \\
\hline OV19 & $\mathrm{CO}_{2}$ & 12 & 0.084 & 0.051 & 1.6 \\
\hline OV4 & mask $_{\mathrm{CW}}$ & 13 & 0.080 & 0.040 & 2.0 \\
\hline OV100 & $a_{\text {nap }} / a_{\mathrm{p}}$ & 14 & 0.075 & 0.017 & 4.4 \\
\hline OV69 & $\mathrm{PSD}_{\text {slope }}$ & 15 & 0.071 & 0.044 & 1.6 \\
\hline OV106 & Isoprene $_{\text {sea }}$ & 16 & 0.071 & 0.028 & 2.6 \\
\hline OV109 & $\mathrm{NCP}$ & 17 & 0.067 & 0.041 & 1.7 \\
\hline OV60 & $\sigma_{0, \mathrm{sw}}$ & 19 & 0.060 & 0.034 & 1.8 \\
\hline OV2 & $P_{\text {air }}$ & 20 & 0.049 & 0.015 & 3.4 \\
\hline OV55 & SSH & 23 & 0.041 & 0.013 & 3.0 \\
\hline OV93 & $\mathrm{POC}$ & 24 & 0.038 & 0.021 & 1.8 \\
\hline
\end{tabular}


Table S8. List of OVs contributing to LV8 - Iron-limited biological productivity, whith $\sigma \bar{w}^{-1}>1$. The OVs are sorted according to $\sigma \bar{w}^{-1}>$ 1 (sixed column). The order rank according to $|w|$ is provided in the third column.

\begin{tabular}{|c|c|c|c|c|c|}
\hline OV-ID & Symbol & Rank & $\bar{w}$ & $\sigma$ & $\sigma \bar{w}^{-1}$ \\
\hline OV82 & Prasino & 1 & 0.283 & 0.010 & 28.6 \\
\hline OV70 & $\mathrm{F}_{\mathrm{V}} \mathrm{F}_{\mathrm{M}}$ & 2 & 0.265 & 0.019 & 14.1 \\
\hline OV74 & Chloro & 3 & 0.259 & 0.023 & 11.3 \\
\hline OV81 & Hapto67 & 4 & 0.259 & 0.012 & 21.9 \\
\hline OV80 & Hapto8 & 5 & 0.251 & 0.015 & 17.0 \\
\hline OV71 & $\Phi_{\mathrm{PSII}}^{\prime}$ & 6 & 0.242 & 0.027 & 8.8 \\
\hline OV100 & $a_{\text {nap }} / a_{\mathrm{p}}$ & 7 & -0.222 & 0.019 & 11.8 \\
\hline OV76 & Cyano & 8 & 0.218 & 0.027 & 8.0 \\
\hline OV53 & $H_{s}$ & 9 & 0.212 & 0.045 & 4.7 \\
\hline OV84 & $N_{\text {totalbacteria }}$ & 10 & 0.206 & 0.032 & 6.5 \\
\hline OV54 & $T_{m-1,1}$ & 11 & 0.198 & 0.042 & 4.7 \\
\hline OV75 & Crypto & 12 & 0.197 & 0.031 & 6.3 \\
\hline OV64 & TChl $a$ & 13 & 0.187 & 0.022 & 8.6 \\
\hline OV105 & $\mathrm{CS}_{2}$ & 14 & 0.182 & 0.008 & 23.1 \\
\hline OV87 & $N_{\text {picoeukaryotes }}$ & 15 & 0.170 & 0.042 & 4.0 \\
\hline OV85 & $N_{\text {synechococcus }}$ & 16 & 0.166 & 0.029 & 5.8 \\
\hline OV106 & Isoprene $_{\text {sea }}$ & 17 & 0.149 & 0.022 & 6.9 \\
\hline OV83 & Pelago & 18 & 0.139 & 0.027 & 5.1 \\
\hline OV1 & $u_{10 \mathrm{~N}}$ & 19 & 0.139 & 0.048 & 2.9 \\
\hline OV79 & Dino & 20 & 0.119 & 0.026 & 4.6 \\
\hline OV36 & $\mathrm{SO}_{4}^{2-}$ & 21 & -0.112 & 0.039 & 2.8 \\
\hline OV19 & $\mathrm{CO}_{2}$ & 22 & 0.106 & 0.086 & 1.2 \\
\hline OV78 & DiatB & 23 & -0.095 & 0.021 & 4.5 \\
\hline OV60 & $\sigma_{0, \mathrm{sw}}$ & 24 & 0.085 & 0.053 & 1.6 \\
\hline OV99 & $a_{\text {napslope }}$ & 25 & -0.081 & 0.038 & 2.1 \\
\hline OV59 & $I_{\mathrm{g}}$ & 26 & -0.078 & 0.064 & 1.2 \\
\hline OV21 & $\mathrm{CO}$ & 27 & 0.076 & 0.042 & 1.8 \\
\hline OV22 & $\mathrm{O}_{3}$ & 28 & 0.069 & 0.043 & 1.6 \\
\hline OV61 & $S_{\mathrm{sw}}$ & 29 & 0.066 & 0.044 & 1.5 \\
\hline OV77 & DiatA & 30 & 0.059 & 0.036 & 1.7 \\
\hline
\end{tabular}


Table S9. Extension of Table S8

\begin{tabular}{llllll}
\hline OV-ID & Symbol & Rank & $\bar{w}$ & $\sigma$ & $\sigma \bar{w}^{-1}$ \\
\hline OV82 & Prasino & 31 & -0.058 & 0.027 & 2.2 \\
OV70 & F $_{\text {V }}$ & 32 & 0.057 & 0.042 & 1.4 \\
OV74 & Chloro & 33 & -0.056 & 0.044 & 1.3 \\
OV81 & Hapto67 & 34 & 0.047 & 0.032 & 1.5 \\
OV80 & Hapto8 & 35 & -0.046 & 0.030 & 1.5 \\
OV71 & $\Phi_{\text {PSII }}$ & 36 & 0.040 & 0.016 & 2.5 \\
OV100 & $a_{\text {nap }} / a_{\mathrm{p}}$ & 37 & 0.038 & 0.025 & 1.5 \\
OV76 & Cyano & 38 & -0.038 & 0.025 & 1.5 \\
OV53 & $H_{s}$ & 39 & 0.026 & 0.024 & 1.1 \\
OV84 & $N_{\text {totalbacteria }}$ & 40 & -0.024 & 0.022 & 1.1 \\
\hline
\end{tabular}

Table S10. List of OVs contributing to LV9 - Marginal sea ice zone and snowfall, whith $\sigma \bar{w}^{-1}>1$. The OVs are sorted according to $\sigma \bar{w}^{-1}>1$ (sixed column). The order rank according to $|w|$ is provided in the third column.

\begin{tabular}{llllll}
\hline OV-ID & Symbol & Rank & $\bar{w}$ & $\sigma$ & $\sigma \bar{w}^{-1}$ \\
\hline OV62 & $C_{i}$ & 1 & 0.535 & 0.101 & 5.3 \\
OV54 & $T_{m-1,1}$ & 2 & 0.353 & 0.121 & 2.9 \\
OV60 & $\sigma_{0, \text { sw }}$ & 3 & -0.351 & 0.060 & 5.9 \\
OV14 & SR & 4 & 0.318 & 0.155 & 2.1 \\
OV61 & $S_{\text {sw }}$ & 5 & -0.311 & 0.059 & 5.2 \\
OV11 & $\delta^{2} \mathrm{H}_{\text {vap }}$ & 6 & -0.228 & 0.092 & 2.5 \\
OV10 & $\delta^{18} \mathrm{O}_{\text {vap }}$ & 7 & -0.218 & 0.087 & 2.5 \\
OV109 & $\mathrm{NCP}$ & 8 & 0.205 & 0.020 & 10.5 \\
OV21 & $\mathrm{CO}$ & 9 & -0.106 & 0.044 & 2.4 \\
OV8 & $\mathrm{RH}$ & 10 & 0.092 & 0.021 & 4.5 \\
OV65 & $\mathrm{Chl} a_{\text {fluo }}$ & 12 & 0.059 & 0.046 & 1.3 \\
\hline
\end{tabular}


Table S11. List of OVs contributing to LV10 - Diel cycle, whith $\sigma \bar{w}^{-1}>1$. The OVs are sorted according to $\sigma \bar{w}^{-1}>1$ (sixed column). The order rank according to $|w|$ is provided in the third column.

\begin{tabular}{llllll}
\hline OV-ID & Symbol & Rank & $\bar{w}$ & $\sigma$ & $\sigma \bar{w}^{-1}$ \\
\hline OV6 & $S_{\text {in }}$ & 1 & 0.649 & 0.013 & 51.0 \\
OV7 & PAR & 2 & 0.623 & 0.007 & 83.7 \\
OV65 & Chl $a_{\text {fluo }}$ & 3 & -0.258 & 0.025 & 10.4 \\
OV38 & $\mathrm{H}_{2} \mathrm{SO}_{4}$ & 4 & 0.200 & 0.024 & 8.4 \\
OV39 & $\mathrm{HIO}_{3}$ & 5 & 0.196 & 0.033 & 5.9 \\
OV71 & $\Phi_{\mathrm{PSII}}$ & 6 & -0.187 & 0.026 & 7.2 \\
OV4 & mask $_{\mathrm{CW}}$ & 7 & 0.061 & 0.015 & 3.9 \\
OV18 & $\mathrm{SC}$ & 8 & -0.049 & 0.036 & 1.4 \\
\hline
\end{tabular}

Table S12. List of OVs contributing to LV11 - Surface nutrient concentrations associated with mixing events, climatic, and frontal zones, whith $\sigma \bar{w}^{-1}>1$. The OVs are sorted according to $\sigma \bar{w}^{-1}>1$ (sixed column). The order rank according to $|w|$ is provided in the third column.

\begin{tabular}{llllll}
\hline OV-ID & Symbol & Rank & $\bar{w}$ & $\sigma$ & $\sigma \bar{w}^{-1}$ \\
\hline OV90 & Phosphate & 1 & 0.468 & 0.070 & 6.7 \\
OV88 & Nitrate & 2 & 0.456 & 0.075 & 6.1 \\
OV52 & $r_{\text {fluo,coarse3 } \sigma}$ & 3 & -0.355 & 0.075 & 4.7 \\
OV89 & Nitrite & 4 & 0.288 & 0.079 & 3.6 \\
OV51 & $r_{\text {fluo,fine3 } \sigma}$ & 5 & -0.280 & 0.251 & 1.1 \\
OV84 & $N_{\text {totalbacteria }}$ & 6 & -0.165 & 0.056 & 2.9 \\
OV65 & Chl $a_{\text {fluo }}$ & 7 & -0.161 & 0.050 & 3.3 \\
OV91 & Silicate & 8 & 0.150 & 0.081 & 1.8 \\
OV54 & $T_{m-1,1}$ & 9 & 0.145 & 0.142 & 1.0 \\
OV93 & POC & 11 & -0.080 & 0.046 & 1.7 \\
OV1 & $u_{10 N}$ & 13 & -0.074 & 0.057 & 1.3 \\
OV74 & Chloro & 14 & -0.066 & 0.034 & 1.9 \\
OV94 & PON & 17 & -0.042 & 0.028 & 1.5 \\
OV86 & $N_{\text {nanoeukaryotes }}$ & 20 & -0.027 & 0.026 & 1.0 \\
\hline
\end{tabular}


Table S13. List of OVs contributing to LV12 - Wind driven conditions and sea spray aerosol, whith $\sigma \bar{w}^{-1}>1$. The OVs are sorted according to $\sigma \bar{w}^{-1}>1$ (sixed column). The order rank according to $|w|$ is provided in the third column.

\begin{tabular}{llllll}
\hline OV-ID & Symbol & Rank & $\bar{w}$ & $\sigma$ & $\sigma \bar{w}^{-1}$ \\
\hline OV26 & $N_{\text {seaspray }}$ & 1 & 0.482 & 0.054 & 9.0 \\
OV37 & $\mathrm{Cl}^{-}$ & 2 & 0.459 & 0.075 & 6.1 \\
OV1 & $u_{10 \mathrm{~N}}$ & 3 & 0.438 & 0.071 & 6.2 \\
OV59 & $I_{\mathrm{g}}$ & 4 & -0.255 & 0.096 & 2.6 \\
OV16 & visibility & 5 & -0.228 & 0.056 & 4.0 \\
OV25 & $N_{\text {accumulation }}$ & 6 & -0.206 & 0.044 & 4.7 \\
OV53 & $H_{s}$ & 7 & 0.174 & 0.073 & 2.4 \\
OV30 & $N_{\text {sodium,PM10 }}$ & 10 & 0.072 & 0.057 & 1.3 \\
OV33 & $N_{\text {magnesium,PM10 }}$ & 11 & 0.068 & 0.054 & 1.3 \\
\hline
\end{tabular}

Table S14. List of OVs contributing to LV13 - Extratropical cyclone activity, whith $\sigma \bar{w}^{-1}>1$. The OVs are sorted according to $\sigma \bar{w}^{-1}>1$ (sixed column). The order rank according to $|w|$ is provided in the third column.

\begin{tabular}{llllll}
\hline OV-ID & Symbol & Rank & $\bar{w}$ & $\sigma$ & $\sigma \bar{w}^{-1}$ \\
\hline OV3 & mask $_{\text {cyc }}$ & 1 & 0.658 & 0.042 & 15.7 \\
OV2 & $P_{\text {air }}$ & 2 & -0.481 & 0.039 & 12.4 \\
OV23 & Isoprene $_{\text {air }}$ & 3 & 0.364 & 0.045 & 8.1 \\
OV77 & DiatA & 4 & -0.169 & 0.084 & 2.0 \\
OV21 & CO & 6 & -0.106 & 0.045 & 2.3 \\
OV36 & $\mathrm{SO}_{4}^{2-}$ & 7 & -0.098 & 0.054 & 1.8 \\
OV63 & $\delta^{18} \mathrm{O}_{\text {sw }}$ & 8 & 0.088 & 0.062 & 1.4 \\
OV18 & $\mathrm{SC}$ & 12 & -0.071 & 0.056 & 1.3 \\
OV75 & Crypto & 13 & -0.065 & 0.056 & 1.2 \\
OV65 & Chl $a_{\text {fluo }}$ & 14 & -0.055 & 0.047 & 1.2 \\
\hline
\end{tabular}


Table S15. List of OVs contributing to LV14 - Climatic zones with local high latitude hotspots, whith $\sigma \bar{w}^{-1}>1$. The OVs are sorted according to $\sigma \bar{w}^{-1}>1$ (sixed column). The order rank according to $|w|$ is provided in the third column.

\begin{tabular}{llllll}
\hline OV-ID & Symbol & Rank & $\bar{w}$ & $\sigma$ & $\sigma \bar{w}^{-1}$ \\
\hline OV24 & $N_{\text {Aitken }}$ & 1 & 0.467 & 0.078 & 6.0 \\
OV56 & $U_{\mathrm{g}}$ & 2 & 0.298 & 0.097 & 3.1 \\
OV43 & $N_{\mathrm{CCN}, 1.00}$ & 3 & 0.295 & 0.050 & 5.9 \\
OV14 & SR & 4 & -0.245 & 0.085 & 2.9 \\
OV91 & Silicate & 5 & -0.240 & 0.065 & 3.7 \\
OV13 & RR & 6 & 0.200 & 0.082 & 2.4 \\
OV109 & NCP & 7 & 0.197 & 0.046 & 4.3 \\
OV46 & $\kappa_{\text {CCN }, 1.00}$ & 8 & 0.157 & 0.076 & 2.1 \\
OV53 & $H_{s}$ & 9 & 0.151 & 0.073 & 2.1 \\
OV75 & Crypto & 10 & -0.142 & 0.082 & 1.7 \\
OV72 & $\sigma_{\text {PSII }}$ & 11 & -0.112 & 0.085 & 1.3 \\
OV73 & $\sigma_{\text {PSII }}$ & 12 & -0.111 & 0.071 & 1.6 \\
OV55 & SSH & 13 & 0.109 & 0.052 & 2.1 \\
OV57 & $T_{\text {sw }}$ & 16 & 0.078 & 0.047 & 1.7 \\
OV9 & $w$ & 17 & 0.075 & 0.049 & 1.5 \\
OV110 & $d_{\text {land }}$ & 19 & 0.066 & 0.022 & 3.0 \\
OV5 & $T_{\text {air }}$ & 22 & 0.063 & 0.052 & 1.2 \\
OV65 & Chl $a_{\text {fluo }}$ & 25 & 0.046 & 0.038 & 1.2 \\
\hline
\end{tabular}


The origin of the air parcels arriving during snowfall along the ACE track differs depending on the arrival altitude and location along the track. Generally, air parcels arriving at low altitudes arrive more often from southerly direction than those arriving above $850 \mathrm{hPa}$ above sea level (a.s.l.) (compare e.g. Figure S5a and b). A strong contrast in the air parcel origin can be seen for the Mertz Glacier area (dark to light blue points in Figure S5). The trajectories arriving below $850 \mathrm{hPa}$ a.s.l. were located 255 over the Antarctica continent $24 \mathrm{~h}$ before arrival (Figure S5c), while the trajectories arriving above $850 \mathrm{hPa}$ were located to the north of the ACE ship track (Figure S5d). 

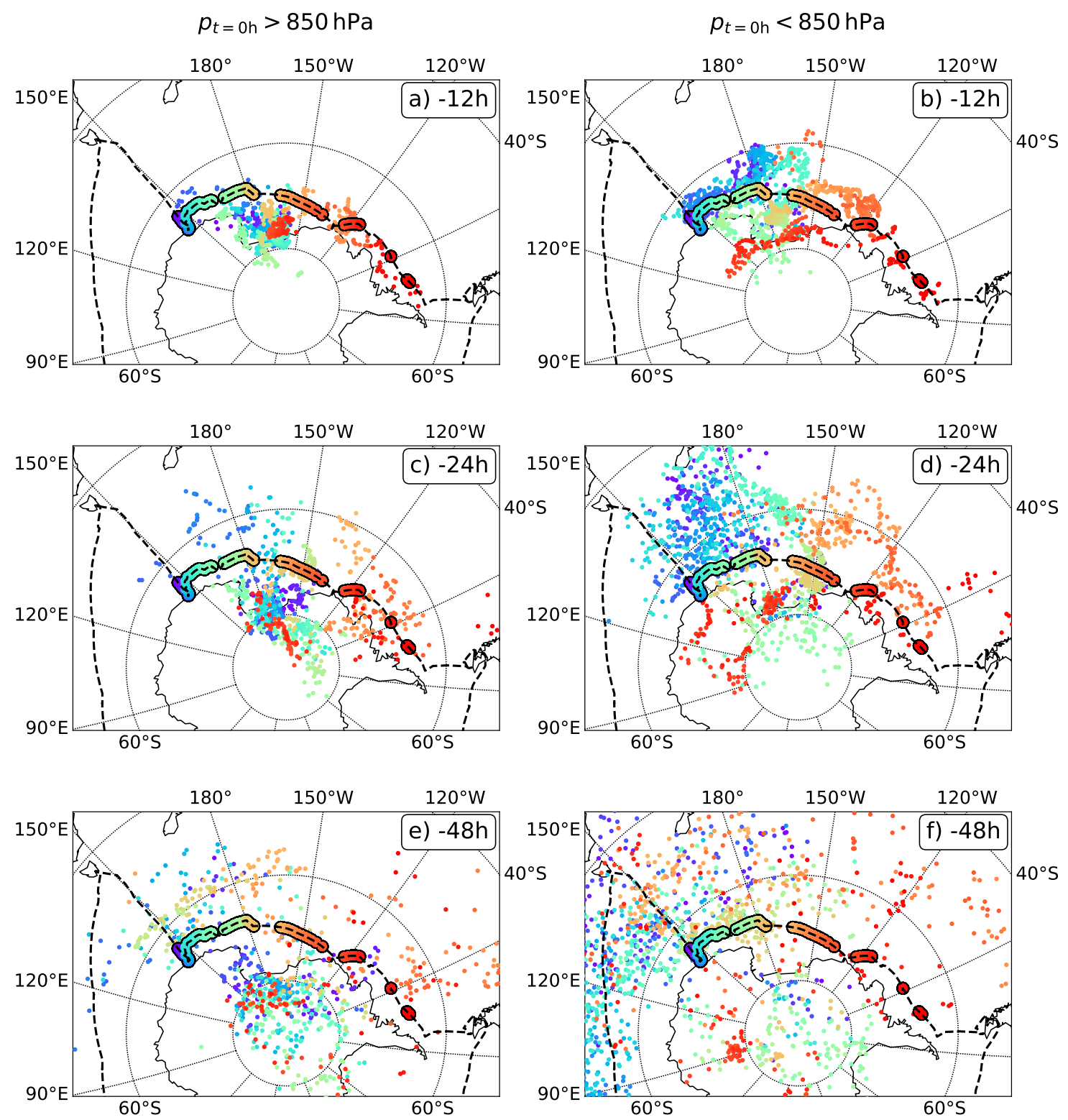

Figure S5. Map plots showing the location (small dots) of backward trajectories (a,b) $12 \mathrm{~h}$, (c,d) $24 \mathrm{~h}$ and (e,f) $48 \mathrm{~h}$ before arrival along the ACE track starting at altitudes (a,c,e) below and (b,d,f) above $850 \mathrm{hPa}$ a.s.l. Only backward trajectories, which arrive during snowfall, are shown. The dashed, black line shows the ACE ship track and the coloured line the starting positions of the backward trajectories along the ACE track. The colours of the small dots correspond to the colours of the trajectories' starting positions, respectively. The backward trajectories were launched between 0 and $500 \mathrm{hPa}$ a.s.l. every hour along the ACE track using the 3D wind fields from ECMWF analysis data. For more details on the trajectory calculations see Thurnherr et al. (2020b). 


\section{References}

Alberello, A., Bennetts, L., and Toffoli, A.: Antarctic Circumnavigation Expedition 2017: Motion Sensor and GPS Data, https://doi.org/10.4225/15/5A178EF0E5156, 2020.

Antoine, D., Thomalla, S., Berliner, D., Little, H., Moutier, W., Olivier-Morgan, A., Robinson, C., Ryan-Keogh, T., and Schuback, N.: Phytoplankton Pigment Concentrations of Seawater Sampled during the Antarctic Circumnavigation Expedition (ACE) during the Austral Summer of 2016/2017., https://doi.org/10.5281/zenodo.3406983, 2019a.

Antoine, D., Thomalla, S., Berliner, D., Little, H., Moutier, W., Olivier-Morgan, A., Robinson, C., Ryan-Keogh, T., and Schuback, N.: Phytoplankton Pigment Concentrations of Seawater Sampled during the Antarctic Circumnavigation Expedition (ACE) during the Austral Summer of 2016/2017., https://doi.org/10.5281/zenodo.3406983, 2019b.

Antoine, D., Thomalla, S., Berliner, D., Little, H., Moutier, W., Olivier-Morgan, A., Robinson, C., Ryan-Keogh, T., and Schuback, N.: Particulate Light Absorption Coefficients (350 - 750 Nm) Measured Using the Filter Pad Method during the Antarctic Circumnavigation Expedition (ACE) during the Austral Summer of 2016/2017., https://doi.org/10.5281/zenodo.3993096, 2021.

Babarit, A. and Delhommeau, G.: Theoretical and numerical aspects of the open source BEM solver NEMOH, in: Proc. of the 11th European Wave and Tidal Energy Conference (EWTEC2015), 2015.

Ball, E. H.: Quantitation of proteins by elution of Coomassie brilliant blue R from stained bands after sodium dodecyl sulfate-polyacrylamide gel electrophoresis, Analytical biochemistry, 155, 23-27, 1986.

Bolas, C. G., Ferracci, V., Robinson, A. D., Mead, M. I., Nadzir, M. S. M., Pyle, J. A., Jones, R. L., and Harris, N. R. P.: iDirac: A FieldPortable Instrument for Long-Term Autonomous Measurements of Isoprene and Selected VOCs, Atmospheric Measurement Techniques, 13, 821-838, https://doi.org/10.5194/amt-13-821-2020, 2020.

Bricaud, A. and Stramski, D.: Spectral Absorption Coefficients of Living Phytoplankton and Nonalgal Biogenous Matter: A Comparison between the Peru Upwelling Areaand the Sargasso Sea, Limnology and Oceanography, 35, 562-582, https://doi.org/10.4319/lo.1990.35.3.0562, 1990.

Cassar, N., Wright, S. W., Thomson, P. G., Trull, T. W., Westwood, K. J., de Salas, M., Davidson, A., Pearce, I., Davies, D. M., and Matear, R. J.: The relation of mixed-layer net community production to phytoplankton community composition in the Southern Ocean, Global Biogeochemical Cycles, 29, 446-462, 2015.

Clementson, L. A., Parslow, J. S., Turnbull, A. R., and Bonham, P. I.: Properties of light absorption in a highly coloured estuarine system in south-east Australia which is prone to blooms of the toxic dinoflagellate Gymnodinium catenatum, Estuarine, Coastal and Shelf Science, 60, 101-112, 2004.

Conen, F., Henne, S., Morris, C. E., and Alewell, C.: Atmospheric ice nucleators active $\geq-12^{\circ} \mathrm{C}$ can be quantified on PM 10 filters, Atmospheric measurement techniques, 5, 321-327, https://doi.org/10.5194/amt-5-321-2012, 2012.

Cook, S. S., Whittock, L., Wright, S. W., and Hallegraeff, G. M.: Photosynthetic pigment and genetic differences between two Southern Ocean morphotypes of Emiliania huxleyi (Haptophyta) 1, Journal of phycology, 47, 615-626, 2011.

de Boyer Montégut, C., Madec, G., Fischer, A. S., Lazar, A., and Iudicone, D.: Mixed layer depth over the global ocean:

An examination of profile data and a profile-based climatology, Journal of Geophysical Research C: Oceans, 109, 1-20, https://doi.org/10.1029/2004JC002378, 2004. 
Derkani, M. H., Alberello, A., Nelli, F., Bennetts, L. G., Hessner, K. G., MacHutchon, K., Reichert, K., Aouf, L., Khan, S. S., and Toffoli, A.: Wind, waves, and surface currents in the Southern Ocean: Observations from the Antarctic Circumnavigation Expedition, Earth System Science Data Discussions, 2020, 1-22, https://doi.org/10.5194/essd-2020-255, 2020.

Fröhlich, R., Cubison, M. J., Slowik, J. G., Bukowiecki, N., Prévôt, A. S. H., Baltensperger, U., Schneider, J., Kimmel, J. R., Gonin, M., Rohner, U., Worsnop, D. R., and Jayne, J. T.: The ToF-ACSM: A Portable Aerosol Chemical Speciation Monitor with TOFMS Detection, Atmospheric Measurement Techniques, 6, 3225-3241, https://doi.org/10.5194/amt-6-3225-2013, 2013.

Gehring, J., Oertel, A., Vignon, É., Jullien, N., Besic, N., and Berne, A.: Microphysics and Dynamics of Snowfall Associated with a Warm Conveyor Belt over Korea, Atmospheric Chemistry and Physics, 20, 7373-7392, https://doi.org/10.5194/acp-20-7373-2020, 2020.

Gorodetskaya, I. V., Kneifel, S., Maahn, M., Van Tricht, K., Thiery, W., Schween, J. H., Mangold, A., Crewell, S., and Van Lipzig, N. P. M.: Cloud and Precipitation Properties from Ground-Based Remote-Sensing Instruments in East Antarctica, The Cryosphere, 9, 285-304, https://doi.org/10.5194/tc-9-285-2015, 2015.

Grazioli, J., Genthon, C., Boudevillain, B., Duran-Alarcon, C., Del Guasta, M., Madeleine, J.-B., and Berne, A.: Measurements of Precipitation in Dumont d'Urville, Adélie Land, East Antarctica, The Cryosphere, 11, 1797-1811, https://doi.org/10.5194/tc-11-1797-2017, 2017.

Haumann, F. A., Leonard, K., Meredith, M. P., Arrowsmith, C., Gorodetskaya, I. V., Hutchings, J., Lehning, M., Leng, M. J., Stammerjohn, S., Tsukernik, M., and Weber, Y.: Seawater stable isotope sample measurements from the Antarctic Circumnavigation Expedition (ACE), https://doi.org/10.5281/zenodo.1494915, 2019.

Haumann, F. A., Leonard, K., Meredith, M. P., Budéus, G., Gorodetskaya, I. V., Hutchings, J., Lehning, M., Stammerjohn, S.,

Tsukernik, M., and Weber, Y.: Seawater salinity sample measurements from the Antarctic Circumnavigation Expedition (ACE), https://doi.org/10.5281/zenodo.1494924, 2020a.

Haumann, F. A., Robinson, C., Thomas, J., Hutchings, J., Pina Estany, C., Tarasenko, A., Gerber, F., and Leonard, K.: Physical and biogeochemical oceanography data from underway measurements with an AquaLine Ferrybox during the Antarctic Circumnavigation Expedition (ACE)., https://doi.org/10.5281/zenodo.3660852, 2020b.

315 Haumann, F. A., Thomas, J., Tsukernik, M., and Leonard, K.: Seawater temperature profiles from Expendable Bathythermograph (XBT) probe deployments during the Antarctic Circumnavigation Expedition (ACE), https://doi.org/10.5281/zenodo.3836648, 2020c.

Henry, T., Robinson, C., Haumann, F. A., Thomas, J., Hutchings, J., Schuback, N., Tsukernik, M., and Leonard, K.: Physical and biogeochemical oceanography data from Conductivity, Temperature, Depth (CTD) rosette deployments during the Antarctic Circumnavigation Expedition (ACE), https://doi.org/10.5281/zenodo.3813646, 2020.

Higgins, H. W., Wright, S. W., and Schlüter, L.: Quantitative Interpretation of Chemotaxonomic Pigment Data, in: Phytoplankton Pigments: Characterization, Chemotaxonomy and Applications in Oceanography, edited by Llewellyn, C. A., Egeland, E. S., Johnsen, G., and Roy, S., Cambridge Environmental Chemistry Series, pp. 257-313, Cambridge University Press, Cambridge, https://doi.org/10.1017/CBO9780511732263.010, 2011.

Khlystov, A., Stanier, C., and Pandis, S.: An algorithm for combining electrical mobility and aerodynamic size distributions data when measuring ambient aerosol special issue of aerosol science and technology on findings from the fine particulate matter supersites program, Aerosol Science and Technology, 38, 229-238, https://doi.org/10.1080/02786820390229543, 2004.

Kirk, J. T. O.: Light and Photosynthesis in Aquatic Ecosystems, Cambridge University Press, 2 edn., https://doi.org/10.1017/CBO9780511623370, 1994.

Köhler, H.: The nucleus in and the growth of hygroscopic droplets, Transactions of the Faraday Society, 32, 1152-1161, 1936. 
Kulie, M. S. and Bennartz, R.: Utilizing Spaceborne Radars to Retrieve Dry Snowfall, Journal of Applied Meteorology and Climatology, 48, 2564-2580, https://doi.org/10.1175/2009JAMC2193.1, 2009.

Landwehr, S., Thomas, J., Gorodetskaya, I., Thurnherr, I., Robinson, C., and Schmale, J.: Quality-Checked Meteorological Data from the Southern Ocean Collected during the Antarctic Circumnavigation Expedition from December 2016 to April 2017. https://doi.org/10.5281/zenodo.3379590, 2019.

Landwehr, S., Thurnherr, I., Cassar, N., Gysel-Beer, M., and Schmale, J.: Using Global Reanalysis Data to Quantify and Correct Airflow Distortion Bias in Shipborne Wind Speed Measurements, Atmospheric Measurement Techniques, 13, 3487-3506, https://doi.org/10.5194/amt-13-3487-2020, 2020.

Maahn, M. and Kollias, P.: Improved Micro Rain Radar Snow Measurements Using Doppler Spectra Post-Processing, Atmospheric Measurement Techniques, 5, 2661-2673, https://doi.org/10.5194/amt-5-2661-2012, 2012.

Mackey, M., Mackey, D., Higgins, H., and Wright, S.: CHEMTAX-a program for estimating class abundances from chemical markers: application to HPLC measurements of phytoplankton, Marine Ecology Progress Series, 144, 265-283, 1996.

Matrosov, S. Y.: Potential for Attenuation-Based Estimations of Rainfall Rate from CloudSat, Geophysical Research Letters, 34, https://doi.org/10.1029/2006GL029161, 2007.

Meier, W., Fetterer, F., Savoie, M., Mallory, S., Duerr, R., and Stroeve, J.: NOAA/NSIDC Climate Data Record of passive microwave sea ice concentration, version 2. 1979-2018, https://doi.org/10.7265/N55M63M1, 2013.

Modini, R. L., Frossard, A. A., Ahlm, L., Russell, L. M., Corrigan, C. E., Roberts, G. C., Hawkins, L. N., Schroder, J. C., Bertram, A. K., Zhao, R., Lee, A. K. Y., Abbatt, J. P. D., Lin, J., Nenes, A., Wang, Z., Wonaschütz, A., Sorooshian, A., Noone, K. J., Jonsson, H., Seinfeld, J. H., Toom-Sauntry, D., Macdonald, A. M., and Leaitch, W. R.: Primary Marine Aerosol-Cloud Interactions off the Coast of California, Journal of Geophysical Research: Atmospheres, 120, 4282-4303, https://doi.org/10.1002/2014JD022963, 2015.

Morel, A.: Optical modeling of the upper ocean in relation to its biogenous matter content (case I waters), Journal of Geophysical Research: Oceans, 93, 10 749-10 768, https://doi.org/https://doi.org/10.1029/JC093iC09p10749, 1988.

Müller, K., Lehmann, S., van Pinxteren, D., Gnauk, T., Niedermeier, N., Wiedensohler, A., and Herrmann, H.: Particle Characterization at the Cape Verde Atmospheric Observatory during the 2007 RHaMBLe Intensive, Atmospheric Chemistry and Physics, 10, 2709-2721, https://doi.org/10.5194/acp-10-2709-2010, 2010.

Nelli, F., Van Zuydam, A., Pferdekamper, K. A., Alberello, A., Derkani, M., Bekker, A., and Toffoli, A.: Reconstructing sea-states in the Southern Ocean using ship motion data, in: ASME 2020 40th International Conference on Ocean, Offshore and Arctic Engineering, 2020. Newman, J. N.: Marine hydrodynamics, MIT press, 2018.

Nunes, S., Latasa, M., Delgado, M., Emelianov, M., Simó, R., and Estrada, M.: Phytoplankton community structure in contrasting ecosystems of the Southern Ocean: South Georgia, South Orkneys and western Antarctic Peninsula, Deep Sea Research Part I: Oceanographic Research Papers, 151, 103 059, 2019.

Orsi, A. H., Whitworth, T., and Nowlin, W. D.: On the meridional extent and fronts of the Antarctic Circumpolar Current, Deep-Sea Research Part I, 42, 641-673, https://doi.org/10.1016/0967-0637(95)00021-W, 1995.

Passow, U. and Alldredge, A. L.: A Dye-Binding Assay for the Spectrophotometric Measurement of Transparent Exopolymer Particles (TEP), Limnology and Oceanography, 40, 1326-1335, https://doi.org/10.4319/lo.1995.40.7.1326, 1995.

Peng, G., Meier, W. N., Scott, D. J., and Savoie, M. H.: A long-term and reproducible passive microwave sea ice concentration data record for climate studies and monitoring, Earth System Science Data, 5, 311-318, https://doi.org/10.5194/essd-5-311-2013, 2013. 
Peters, G., Fischer, B., Münster, H., Clemens, M., and Wagner, A.: Profiles of Raindrop Size Distributions as Retrieved by Microrain Radars, Journal of Applied Meteorology and Climatology, 44, 1930-1949, https://doi.org/10.1175/JAM2316.1, 2005.

Petters, M. D. and Kreidenweis, S. M.: A single parameter representation of hygroscopic growth and cloud condensation nucleus activity, Atmospheric Chemistry and Physics, 7, 1961-1971, <GotoISI>://000246455500005, 2007.

Pruppacher, H. and Klett, J.: Microphysics of Clouds and Precipitation, Kluwer Acad., Norwell, Mass., 1997.

Reynolds, R. W., Smith, T. M., Liu, C., Chelton, D. B., Casey, K. S., and Schlax, M. G.: Daily high-resolution-blended analyses for sea surface temperature, Journal of Climate, 20, 5473-5496, https://doi.org/10.1175/2007JCLI1824.1, 2007.

Ribal, A. and Young, I. R.: 33 years of globally calibrated wave height and wind speed data based on altimeter observations, Scientific data, 6, 77, 2019.

Roberts, G. and Nenes, A.: A continuous-flow streamwise thermal-gradient CCN chamber for atmospheric measurements, Aerosol Science and Technology, 39, 206-221, https://doi.org/10.1080/027868290913988, 2005.

Rodriguez, F., Varela, M., and Zapata, M.: Phytoplankton assemblages in the Gerlache and Bransfield Straits (Antarctic Peninsula) determined by light microscopy and CHEMTAX analysis of HPLC pigment data, Deep Sea Research Part II: Topical Studies in Oceanography, 49, 723-747, 2002.

Roesler, C. S. and Barnard, A. H.: Optical proxy for phytoplankton biomass in the absence of photophysiology: Rethinking the absorption line height, Methods in Oceanography, 7, 79-94, 2013.

Ryan-Keogh, T. J. and Robinson, C. M.: Phytoplankton Photophysiology Utilities: A Python Toolbox for the standardisation of processing active chlorophyll fluorescence data, submitted to Frontiers in Marine Science, Aquatic Physiology, 2021.

Schmale, J., Henning, S., Henzing, B., Keskinen, H., Sellegri, K., Ovadnevaite, J., Bougiatioti, A., Kalivitis, N., Stavroulas, I., Jefferson, A., et al.: Collocated observations of cloud condensation nuclei, particle size distributions, and chemical composition, Scientific data, 4 , $170003,2017$.

Schmale, J., Baccarini, A., Thurnherr, I., Henning, S., Efraim, A., Regayre, L., Bolas, C., Hartmann, M., Welti, A., Lehtipalo, K., Aemisegger, F., Tatzelt, C., Landwehr, S., Modini, R. L., Tummon, F., Johnson, J. S., Harris, N., Schnaiter, M., Toffoli, A., Derkani, M., Bukowiecki, N., Stratmann, F., Dommen, J., Baltensperger, U., Wernli, H., Rosenfeld, D., Gysel-Beer, M., and Carslaw, K. S.: Overview of the Antarctic Circumnavigation Expedition: Study of Preindustrial-like Aerosols and Their Climate Effects (ACE-SPACE), Bulletin of the American Meteorological Society, 100, 2260-2283, https://doi.org/10.1175/BAMS-D-18-0187.1, 2019.

Souverijns, N., Gossart, A., Lhermitte, S., Gorodetskaya, I. V., Kneifel, S., Maahn, M., Bliven, F. L., and van Lipzig, N. P. M.: Estimating Radar Reflectivity - Snowfall Rate Relationships and Their Uncertainties over Antarctica by Combining Disdrometer and Radar Observations, Atmospheric Research, 196, 211-223, https://doi.org/10.1016/j.atmosres.2017.06.001, 2017.

Sprenger, M. and Wernli, H.: The LAGRANTO Lagrangian Analysis Tool - Version 2.0, Geoscientific Model Development, 8, 2569-2586, https://doi.org/10.5194/gmd-8-2569-2015, 2015.

Sprenger, M., Fragkoulidis, G., Binder, H., Croci-Maspoli, M., Graf, P., Grams, C. M., Knippertz, P., Madonna, E., Schemm, S., Škerlak, B., and Wernli, H.: Global Climatologies of Eulerian and Lagrangian Flow Features Based on ERA-Interim, Bulletin of the American Meteorological Society, 98, 1739-1748, https://doi.org/10.1175/BAMS-D-15-00299.1, 2017.

Thomalla, S., Antoine, D., Berliner, D., Little, H., Moutier, W., Olivier-Morgan, A., Robinson, C., Ryan-Keogh, T., and Schuback, N.: Sky Irradiance over Photosynthetically Active Radiation Wavelengths (400-700 Nm) Recorded Shipboard during the Antarctic Circumnavigation Expedition (ACE) during the Austral Summer of 2016/2017., https://doi.org/10.5281/zenodo.3859836, 2020. 
Thomas, J. and Pina Estany, C.: Quality-checked, one-minute resolution cruise track of the Antarctic Circumnavigation Expedition (ACE) undertaken during the austral summer of 2016/2017., https://doi.org/10.5281/zenodo.3483166, 2019.

Thurnherr, I., Kozachek, A., Graf, P., Weng, Y., Bolshiyanov, D., Landwehr, S., Pfahl, S., Schmale, J., Sodemann, H., Steen-Larsen, H. C., Toffoli, A., Wernli, H., and Aemisegger, F.: Meridional and Vertical Variations of the Water Vapour Isotopic Composition in the Marine Boundary Layer over the Atlantic and Southern Ocean, Atmospheric Chemistry and Physics, 20, 5811-5835, https://doi.org/10.5194/acp20-5811-2020, 2020a.

Thurnherr, I., Wernli, H., and Aemisegger, F.: 10-day backward trajectories from ECMWF analysis data along the ship track of the Antarctic Circumnavigation Expedition in austral summer 2016/2017., https://doi.org/10.5281/zenodo.4031705, The Antarctic Circumnavigation Expedition was made possible by funding from the Swiss Polar Institute and Ferring Pharmaceuticals. The authors acknowledge MeteoSwiss and ECMWF for the access to the ECMWF operational analyses and forecasts., $2020 \mathrm{~b}$.

Van Pinxteren, M., Barthel, S., Fomba, K. W., Müller, K., Von Tümpling, W., and Herrmann, H.: The influence of environmental drivers on the enrichment of organic carbon in the sea surface microlayer and in submicron aerosol particles-measurements from the Atlantic Ocean, Elementa: Science of the Anthropocene, 5, 35, https://doi.org/10.1525/elementa.225, 2017.

Walton, D. W. H. and Thomas, J.: Cruise Report - Antarctic Circumnavigation Expedition (ACE) 20th December 2016 - 19th March 2017, Tech. rep., Swiss Polar Insitute, https://doi.org/10.5281/zenodo.1443511, 2018.

Weingartner, E., Nyeki, S., and Baltensperger, U.: Seasonal and diurnal variation of aerosol size distributions $(10<\mathrm{D}<750$ $\mathrm{nm}$ ) at a high-alpine site (Jungfraujoch $3580 \mathrm{~m}$ asl), Journal of Geophysical Research: Atmospheres, 104, 26809-26820, https://doi.org/10.1029/1999JD900170, 1999.

Wernli, H. and Davies, H. C.: A Lagrangian-Based Analysis of Extratropical Cyclones. I: The Method and Some Applications, Quarterly Journal of the Royal Meteorological Society, 123, 467-489, https://doi.org/10.1002/qj.49712353811, 1997.

Wernli, H. and Schwierz, C.: Surface Cyclones in the ERA-40 Dataset (1958-2001). Part I: Novel Identification Method and Global Climatology, Journal of the Atmospheric Sciences, 63, 2486-2507, https://doi.org/10.1175/JAS3766.1, 2006.

Zapata, M., Rodríguez, F., and Garrido, J. L.: Separation of chlorophylls and carotenoids from marine phytoplankton: a new HPLC method using a reversed phase C8 column and pyridine-containing mobile phases, Marine Ecology Progress Series, 195, 29-45, 2000. 